\title{
Anabases
}

ANABASES Traditions et réceptions de l'Antiquité

$30 \mid 2019$

Varia

\section{Laurent OLIVIER (dir.), La mémoire et le temps.}

L'

Hubert (1872-1927) œuvre transdisciplinaire d'Henri

Sarah Rey

\section{CpenEdition}

Journals

Édition électronique

URL : https://journals.openedition.org/anabases/10253

DOI : 10.4000/anabases. 10253

ISSN : 2256-9421

Éditeur

E.R.A.S.M.E.

Édition imprimée

Date de publication : 21 octobre 2019

Pagination : 251-253

ISSN : 1774-4296

\section{Référence électronique}

Sarah Rey, « Laurent OLivien (dir.), La mémoire et le temps. L'œuure transdisciplinaire d'Henri Hubert (1872-1927) », Anabases [En ligne], 30 | 2019, mis en ligne le 21 octobre 2019, consulté le 08 novembre 2021. URL : http://journals.openedition.org/anabases/10253 ; DOI : https://doi.org/10.4000/ anabases. 10253 

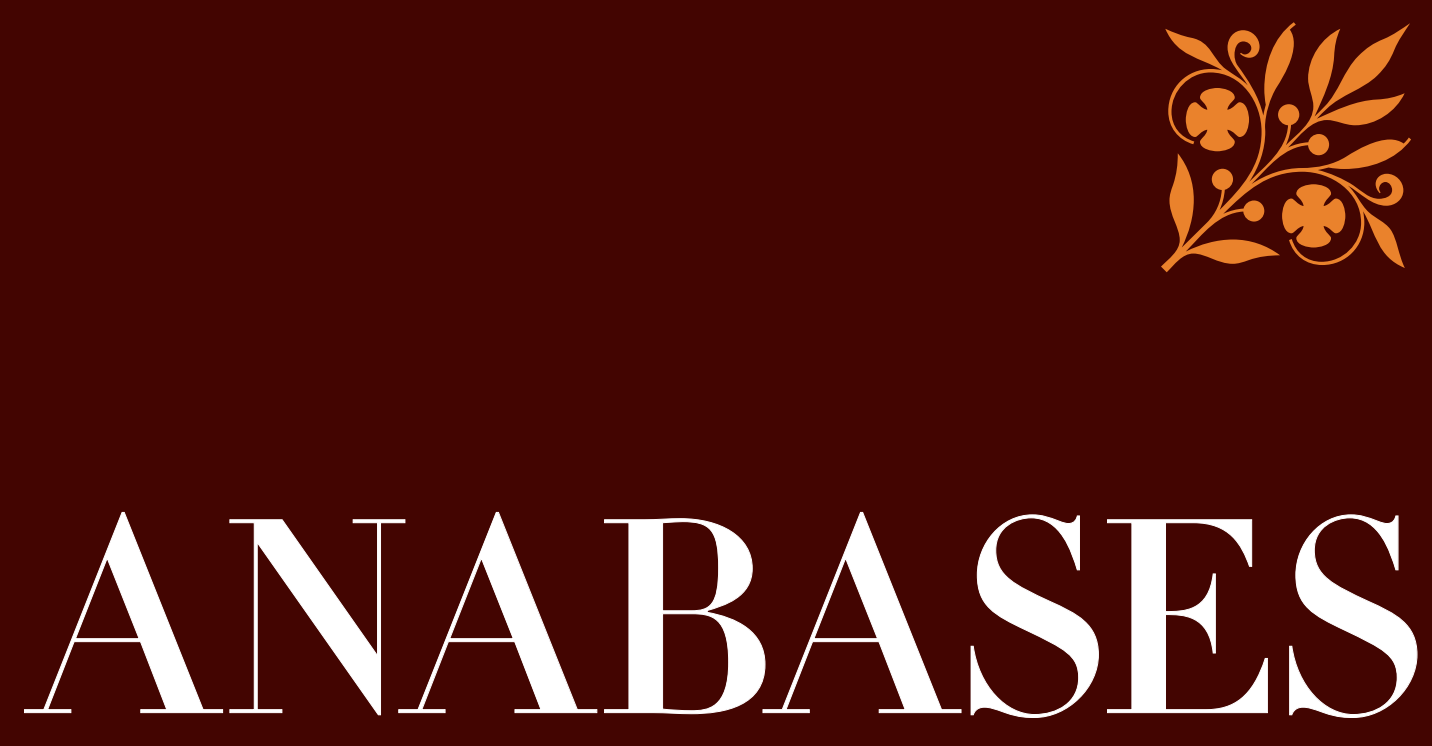

Traditions et Réceptions de l'Antiquité

\section{$\mathrm{N} \times 30$ \\ 2019}

Le sanctuaire de Gournay-sur-Aronde Le pindarisme et l'archéologie musicale Hélène en Égypte Perpétuer Ovide aux $X I V^{e}-X V I I I^{e}$ siècles II classico si fa pop Relire Marcel Detienne Freud à Pompéi 
ANABASES

Traditions et Réceptions de l'Antiquité

Revue de l'équipe de recherche E.R.A.S.M.E.

Université Toulouse-Jean Jaurès (UT2J)

Anabases dispose d'un Comité de lecture international. Chaque article envoyé à la rédaction est soumis, une fois anonymisé, à l'expertise de deux spécialistes qui rendent un rapport écrit. Les deux rapports anonymisés sont transmis à l'auteur qui tient compte des observations en vue de la publication.

\section{Comité SCIENTIFIQue}

Germaine Aujac (université Toulouse-Jean Jaurès : histoire de la géographie et des sciences antiques)

Florence Bouchet (université Toulouse-Jean Jaurès : littérature médiévale)

Hinnerk Brunns (CNRS : histoire économique et sociale ancienne et contemporaine)

Paulo Butti de Lima (université de Bari : historiographie et réception de l'Antiquité)

Luciano CANFora (université de Bari : littérature et histoire anciennes, historiographie)

Giovanna Ceserani (Stanford University : histoire intellectuelle et historiographie de la tradition classique)

Temístocles Cezar (université de Porto Alegre : historiographie moderne)

Serafina Сuомо (University of London, Birkbeck College : histoire des mathématiques et des sciences)

Paul Demont (université de Paris Sorbonne : philologie grecque et héritage classique)

Marie-Laurence Desclos (université de Grenoble II : philosophie de l'Antiquité)

Olivier Devillers (université de Bordeaux 3 - Michel-de-Montaigne : littérature et historiographie latines)

Andrea Giardina (Istituto italiano di scienze umane : histoire du monde romain et de ses réceptions)

Ève Gran-Aymerich (AIBL : histoire de l'archéologie et des transferts culturels)

François Hartog (eHess : historiographie ancienne et moderne)

Geneviève Hoffmann (université de Picardie : histoire des mondes grecs)

Christian JACOB (CNRS/EHESS : histoire comparée et épistémologie des savoirs)

Suzanne Marchand (Louisiana State University : histoire du classicisme et de l'orientalisme)

Wilfried NIPPEL (Humboldt Universität Berlin : histoire et historiographie de l'Antiquité)

Sylvie Pitria (université de Paris I-Panthéon Sorbonne : histoire et historiographie du monde romain)

Stéphane Ratтi (université de Franche-Comté - Besançon : philologie et héritage latin)

Comité de RÉdACtion

Clément Bertau-Courbières, Corinne Bonnet, Laurent bricault, Clément Bur, Adeline Grand-Clément, Anne-Hélène Klinger-Dollé, Véronique Krings, Thibaud Lanfranchi, Pascal Payen, Grégory Reimond, Sarah Rey, Catherine Valenti, Noémie VillacèQue

ÉditeUr RESPONSABLE

Clément Bur

Éditrice ADJOINTE

Catherine VALENTI

Sites Web

http://plh.univ-tlse2.fr

Revues.org : http://anabases.revues.org

Aвonnement et vente aU numéro

Éditions De Boccard - 4, rue de Lanneau - 75005 Paris

info@deboccard.com - www.deboccard.com

Tél. : 0033/(0)143260037 - Fax : 0033/(0)143548583 




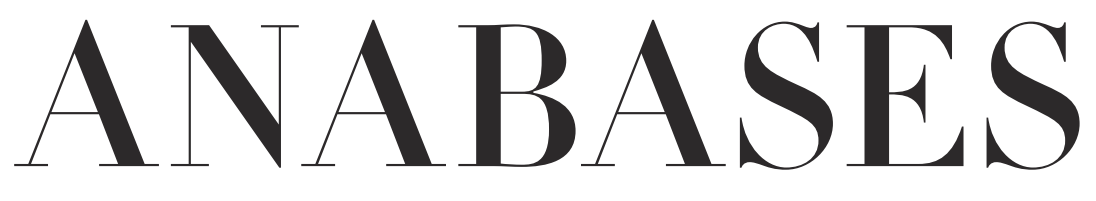

Traditions et Réceptions de l'Antiquité

$$
\begin{aligned}
& N \circ 30 \\
& 2019
\end{aligned}
$$

\section{E.R.A.S.M.E.}

Université Toulouse - Jean Jaurès 



\section{Sommaire}

ํo30 - 2019

\section{Historiographie et identités culturelles}

\section{Carole Quatrelivre}

Le sanctuaire gaulois de Gournay-sur-Aronde (Oise).

Retour sur une découverte exceptionnelle des années I970 . . . . . . . . II

\section{Traditions du patrimoine antique}

Christophe Corbier

Le pindarisme et l'archéologie musicale : style, valeur et authenticité

de la première Pythique à l'époque moderne . . . . . . . . . . . . . . .

Arnaud AmiLIEN

Hélène en Égypte : Hérodote en dialogue avec l’épopée . . . . . . . . . .

\section{Archéologie des savoirs}

Sébastien Cazalas

Au jardin des exempla. Rhétorique et stratégie de l'exemplum antique

dans l'œuvre politique de Jean Juvénal des Ursins (I388-ı473) . . . . . . 7 7

Dossier - Perpétuer Ovide : aspects moraux, éditoriaux,

linguistiques et culturels $\left(\mathrm{XIV}^{\mathrm{e}}-\mathrm{XVIII}^{\mathrm{e}} \mathrm{s}\right.$.)

Francesca Dell'Oro

Introduction $\ldots \ldots \ldots \ldots$. . . . . . . . . . . . . . 89

Hélène Casanova-Robin

L’audace châtiée : Phaéton, Actéon et Icare dans la tradition latine jusqu'à la Renaissance, tours et détours d'un symbolisme . . . . . . . . 9 93 
Dylan Bovet

Le commentaire latin des Métamorphoses d'Ovide : pratiques humanistes et évolutions de Regius-Micyllus (I543) à Burmann-Heinsius (I727) . . . . III

Martine FurNo

Ovide en classe, ou un auteur en éclats . . . . . . . . . . . . . I27

Basil NELIS

D’un Ovide chrétien à un Ovide burlesque, du Moyen Âge au Grand Siècle : continuités et changements dans la traduction et dans l'illustration des Métamorphoses perçus à travers deux éditions du xvII ${ }^{\mathrm{e}}$ siècle . . . . . . . I I43

Olivier ThÉvenAz

Épilogue ....................... I6

\section{Actualités et débats}

Tiphaine-Annabelle BEsnard

2019 : l'année pop des musées d'archéologie. Retour sur l'exposition

romaine Il classico sifa pop. Di scavi, copie e altripasticci . . . . . . . . . . I I7I

\section{Lire, relire la bibliothèque des sciences de l'Antiquité}

Jean-Pierre Albert

Le premier Detienne : une relecture de

“ La notion mythique d"A $\lambda \hat{n} \theta \varepsilon 1 \alpha$ » $\left(R E G\right.$, I96o, p. 27-35) . . . . . . . . . . $\quad{ }_{779}$

Marcel Detienne

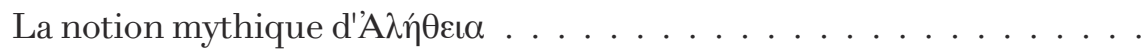

\section{Ateliers de l'histoire}

Antiquités numériques (coordonné par Elodie Guillon) ( $n^{\circ} 1$ )

Élodie GuILlon

Introduction

Jaime Alvar

Le projet EPIDI : Epítetos divinos.

Experiencia religiosa y relaciones de poder en Hispania . . . . . . . . . . . I98 Les mots de l'Antiquité (coordonné par Magali Soulatges) ( $n^{\circ} 10$ )

Jack Thомаs

L’Antiquité dans les toponymes de l'État de New York . . . . . . . . . . . 202

Actualité du théâtre (coordonné par Malika Bastin-Hammou) ( $\left.n^{\circ} 4\right)$

Mathieu FERrand

“ Avons-nous perdu le Soleil ? / Ou l'avons-nous chassé ? » 
Thyeste de Sénèque, traduit par Florence Dupont.

Mise en scène de Thomas Jolly (Avignon, 20I8) . . . . . . . . . . . . . 2 2I4

Voyages et Voyageurs (coordonné par Véronique Krings) ( $n^{\circ} 11$ )

Claude AzIzA

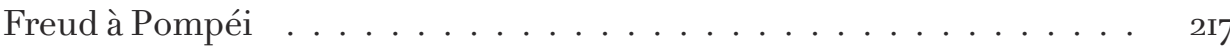

\section{Comptes rendus}

Lucile Arnoux-Farnoux et Polina Kosmadaki (dir.)

Le double voyage : Paris-Athènes (Igrg-Ig39) (Catherine Valenti) . . . . . . 225

Sandra Boehringer et Daniele Lorenzini (dir.)

Foucault, la sexualité, l'Antiquité (Jan Nelis) . . . . . . . . . . . . . . . . 226

Corinne Bonnet, Nicole Belayche, Marlène Albert Llorca,

Alexis Avdeeff, Francesco Massa, Iwo Slobodzianex (dir.)

Puissances divines à l'épreuve du comparatisme. Constructions,

variations et réseaux relationnels (Geneviève Hoffmann) . . . . . . . . . . 228

Shane ButLer (éd.)

Deep Classics, Rethinking Classical Reception (Jan Nelis) . . . . . . . . . . 23o

Zeynep ÇELIK

About Antiquities: Politics of Archaeology in the Ottoman Empire (Jorge Elices Ocón) . . . . . . . . . . . . . . . . . 231

Xavier Deru et Germaine Leman-Delerive (éd),

Franz Cumont, Comment la Belgique fut romanisée (Vivien Barrière) . . . 234

Olivier Devillers, Breno Battistin Sebastiani (éd.)

Sources et modèles des historiens anciens (Arnaud Saura-Ziegelmeyer) . . $\quad 235$

Mara Fazio, Pierre Frantz et Vincenzo De Santis (dir.)

Les Arts du spectacle et la référence antique dans le théâtre

européen (I760-I830) (Arnaud Saura-Ziegelmeyer) . . . . . . . . . . . . . . 237

Jérémy Guedu et Barbara Meazzi (dir.)

La culture fasciste entre latinité et méditerranéité (I880-1940), in Cahiers de la Méditerranée 95, (Andrea Avalli) . . . . . . . . . . . . . . . 239

Marie-Laurence HAAck (éd.), avec la collaboration de Martin MiLler, Les Étrusques au temps du fascisme et du nazisme (Jan Nelis) . . . . . . . . . 24I

Arlene Holmes-Henderson, Steven Hunt et Mai Musié (éd.)

Forward with Classics. Classical Languages in Schools and Communities

(Charlotte Tournier) . . . . . . . . . . . . . . . . . . . . . . .

Daniel Jew, Robin Osborne et Michael Scotт (éd.)

M. I. Finley. An Ancient Historian and his Impact (Hinnerk Bruhns) . . . . $\quad 244$ 
Kostas Kalimtzis,

An inquiry into the philosophical concept of scholê.

Leisure as a Political End (Florent Rouzade) . . . . . . . . . . . . . . . . . 246

Anne-Hélène KLINGER-Dollé

Le De sensu de Charles de Bovelles. Conception philosophique

des sens et figuration de la pensée. Suivi du texte latin du De sensu,

traduit et annoté (Laure Hermand-Schebat) . . . . . . . . . . . . . 248

Egidia Occhipinti

The Hellenica Oxyrhynchia and Historiography:

New Research Perspectives (Anne de Cremoux) . . . . . . . . . . . . . . . . 249

Laurent OLIVIER (dir.)

La mémoire et le temps. L'ouvre transdisciplinaire

d'Henri Hubert (I872-I927) (Sarah Rey) . . . . . . . . . . . . . . . 25I

Gabriella Pinonti et Corinne Bonnet (dir.),

Les dieux d'Homère. Polythéisme et poésie en Grèce ancienne,

Kernos, Supplément 3r. (Sandya Sistac) . . . . . . . . . . . . . . . 253

Rabun TAYLoR, Katherine W. Rinne et S. Kostof

Rome. An Urban History from Antiquity to the Present

(Cyrielle Landrea) . . . . . . . . . . . . . . . . . . . 255

Wyger Velema et Arthur Weststeisn (éd.)

Ancient Models in the Early Modern Republican Imagination

(Paulo Butti de Lima) . . . . . . . . . . . . . . . . . . . 256

Philip WaLsh (éd.)

Brill's Companion to the Reception of Aristophanes

(Malika Bastin-Hammou) . . . . . . . . . . . . . . .

Richard WARren

Art Nouveau and the Classical Tradition (Lucien Calvié) . . . . . . . . . 26o

Jesse Weiner, Benjamin Eldon Stevens et Brett M. Rogers (éd.)

Frankenstein and Its Classics. The Modern Prometheus

from Antiquity to Science Fiction (Mathieu Scapin) . . . . . . . . . . . . . 26r

Nigel G. WiLson

From Byzantium to Italy. Greek Studies in the Italian Renaissance,

deuxième édition (Luigi-Alberto Sanchi) . . . . . . . . . . . . . . 262

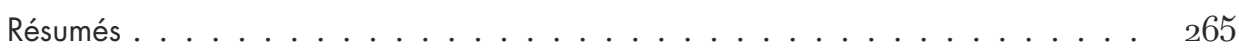

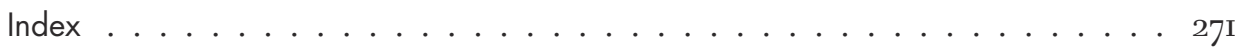




\section{Comptes rendus de lecture}



Lucile Arnoux-Farnoux

et Polina Kosmadaki (dir.), Le double voyage : Paris-Athènes (IgrgI939), Athènes, École française d'Athènes, 20I8, 486 p., $45 €$ / ISBN 9782869582965 .

Publié par l'École française d'Athènes, dans la collection « Mondes méditerranéens et balkaniques », le présent volume, qui traite des relations culturelles francohelléniques pendant la période de l'entredeux-guerres, réunit les actes d'un colloque organisé à Athènes en janvier 2012, luimême précédé entre 2008 et 2010 par une série de journées d'études consacrées notamment aux voyages en Grèce dans les années 1930, à l'Antiquité grecque entre I9I9 et I939, ou encore aux “ Fêtes delphiques » en tant que rencontres internationales des lettres et des arts. C'est donc le fruit d'une réflexion de longue haleine qui nous est proposé ici.

Lucile Arnoux-Farnoux, qui a co-dirigé l'ouvrage et signe l'une des contributions sur la traduction en français de l'œuvre du poète grec Costis Palamas (I859I943) -, évoque en introduction " un sujet méconnu ». Or le thème de l'ouvrage en lui-même - l'influence réciproque que la France et la Grèce ont exercé l'une sur l'autre à l'époque contemporaine - n'est en réalité guère original : on connaît depuis longtemps la fascination pour la France de bon nombre d'intellectuels grecs, et ce depuis la Révolution française; quant à la passion philhellène française, qui a débuté au moment de la guerre d'indépendance contre les Ottomans dans les années I820, elle est également assez bien documentée.

Parmi une bibliographie abondante sur la question, il suffit de citer les travaux de Sophie Basch - d'ailleurs présente dans le volume à travers une contribution sur «La Grèce romanesque de l'entre-deuxguerres »: après un essai sur Les écrivains français en Grèce au xx siècle, paru en I990, elle a publié en 1995 une somme qui fait toujours autorité sur Le mirage grec. La Grèce moderne devant l'opinion française (I846-1946), ouvrage dans lequel elle analyse sur un siècle, depuis la fondation de l'École française d'Athènes en I846 jusqu'aux lendemains de la Seconde Guerre mondiale, l'alternance du philhellénisme et du mishellénisme français. Enfin Sophie Basch a organisé en 2004 à l'École française d'Athènes, avec Alexandre Farnoux, un colloque autour de la revue Le voyage en Grèce, qui a amorcé une nouvelle façon d'envisager les relations culturelles entre la France et la Grèce, comme Lucile ArnouxFarnoux le signale d'ailleurs elle-même dans l'introduction.

Cen'est donc pas dans le sujet de l'ouvrage que réside son originalité, mais bien plutôt dans la volonté d'envisager la période de l'entre-deux-guerres, cadre chronologique auquel se plient toutes les contributions, comme un moment particulier des relations franco-helléniques, une sorte d'apogée dans l'influence réciproque entre les deux pays. Car si la relation peut sembler inégale entre une capitale française qui est alors un foyer culturel d'envergure internationale, attirant des artistes du monde entier, et 
une capitale grecque dont le rayonnement semble moindre, c'est bien d'un échange entre Paris et Athènes qu'il s'agit ici, comme le souligne la problématique du "double voyage ». De même, le parti pris de s'en tenir aux seuls aspects culturels de la relation entre les deux pays ne se révèle pas restrictif, bien au contraire : au-delà des thèmes bien connus de la littérature, de l'architecture et de la peinture, il permet d'aborder des domaines qui le sont beaucoup moins dans ce contexte, comme les arts plastiques, la photographie, le cinéma, la musique ou bien encore les arts décoratifs.

C'est d'ailleurs cette perspective thématique qui est adoptée comme plan de l'ouvrage : après deux contributions inaugurales qui reviennent sur le contexte politico-diplomatique de l'époque, afin de poser le cadre dans lequel se sont déroulés les échanges culturels de la période 19191939, les contributions sont ensuite classées en fonction du champ culturel abordé. Si ce découpage a le mérite de la clarté, il nuit un peu au propos même de l'ouvrage, qui consistait à mettre en valeur un jeu de miroirs et d'influences réciproques: au lecteur de reconstituer, au fil de sa propre lecture, les fluctuations chronologiques de ce double voyage entre Paris et Athènes.

Agrémenté d'illustrations relativement nombreuses, le volume est complété par un index ainsi qu'une bibliographie. On aurait aimé que cette dernière distingue entre les publications datant de la période étudiée qui sont ici des sources -, et les ouvrages contemporains qui relèvent effectivement de la perspective bibliographique: ainsi aurait-on évité de voir se côtoyer Maurice Barrès et Roland Barthes. Enfin, il aurait fallu citer, et utiliser, l'importante thèse de Jean-Claude Montant sur La propagande extérieure de la France pendant la Première Guerre mondiale, en particulier la partie que Montant consacre à la Grèce : comme le rappellent certains des contributeurs euxmêmes, le premier conflit mondial a en effet posé les jalons institutionnels des échanges culturels qui interviendront par la suite.

Dans l'introduction, Lucile ArnouxFarnoux rappelait l'ambition de l'œuvre entreprise: “ devenir un ouvrage de référence pour un public très large, en France et en Grèce ». Si le volume, malgré quelques défauts, sera sans conteste utile au chercheur intéressé par ces thématiques, il n'est pas certain en revanche que son audience dépasse celle des spécialistes de la question.

$$
\begin{array}{r}
\text { Catherine VALENTI } \\
\text { Université de Toulouse-Jean Jaurès } \\
\text { cvalenti@univ-tlse2.fr }
\end{array}
$$

\section{Sandra Boenringer et Daniele Lorenzini (dir.), Foucault, la sexualité, l'Antiquité, Paris, Éditions Kimé, 2oi6, Ig6 p., $20 € /$ ISBN 9782841747399 .}

Foucault, la sexualité, l'Antiquité, édité par Sandra Boehringer et Daniele Lorenzini, se propose d'offrir une mise à jour de la pensée foucaldienne en matière de sexualité, autrement dit de son dernier " grand chantier ", resté inachevé, à savoir la publication de L'Histoire de la sexualité (ensuite $H S$ ). Nous pouvons le dire d'emblée, le livre est une réussite, à la fois au niveau de la qualité des contributions individuelles, de la clarté de leur discours mais aussi de leur complémentarité. Une œuvre qui se révèle, sinon exhaustive-entreprise qui serait aussi naïve qu'impossible à entreprendre-en tout cas très riche et condensée.

Le livre commence par une belle introduction, en deux volets, par Sandra Boehringer, Daniele Lorenzini et Frédéric Gros. Sandra Boehringer et Daniele Lorenzini retracent le sort de $H S$ sur une trentaine d'années, depuis la parution du premier tome jusqu'à aujourd'hui. Ils illustrent la grande richesse de l'œuvre ainsi que son ouverture disciplinaire, 
menant à ce que Foucault qualifiait de "dé-disciplinarisation", fait rare pour l'époque, voire, dans certains contextes, encore aujourd'hui. Une introduction, suivie d'une belle bibliographie qui replace $H S$ dans le contexte de la pensée philosophique et historique de Foucault et montre aussi de façon percutante la réception de cette œuvre non seulement dans les études scientifiques, mais aussi plus largement dans la société. Le fait que Foucault n'ait pas ou presque pas pu répondre aux critiques et commentaires soulevés par la publication de $H S$, alors qu'il en avait l'habitude, justifie d'autant plus l'existence même de ce volume. Cela est d'autant plus évident pour la deuxième partie de l'introduction, dans laquelle Frédéric Gros, entre autres sur base de matériaux d'archives, analyse la genèse intellectuelle de l'ouvrage.

Le premier article (Sandra Boehringer) de la première partie, intitulée Avant la sexualité, analyse le contexte socio-historique dans lequel Foucault développa sa pensée. Enrichi d'une très belle bibliographie, cet article sert à la fois à historiciser la publication de $H S$ et à montrer que sa pertinence perdure aujourd'hui encore, notamment en France - l'exemple le plus éloquent étant la soi-disantManifpourtous. Sandra Boehringer montre aussi comment Foucault en est arrivé à inclure l'Antiquité dans son œuvre, à savoir par la sociologie contemporaine, et non pas sous l'influence de la recherche historique ou encore philologique de son époque. Finalement, l'importance du travail de Kenneth Dover, qui reviendra dans plusieurs autres contributions, est démontrée. Après une étude de la main de Kirk Ormand, qui analyse dans la pensée de Sénèque une forme de subjectivité en lien avec la sexualité, la deuxième partie, titrée C'est à quel sujet ?, consiste en deux articles. La brève étude de Jean Allouch montre avant tout la valeur pour ainsi dire universelle de l'Antiquité pour la pensée de Foucault en matière de sexualité, une pensée qui rapprochait passé et présent. Car en effet, “ l'exactitude du savoir lui importait beaucoup. Cependant, c'était non pas seulement le savoir, mais un souci de vérité, et d'une vérité qui faisait appel au courage, donc une vérité d'opposition, qui l'incitait à publier. Ses livres étaient autant d'interventions dans le présent »(p. 9o). Claude Calame poursuit avec l'une des rares études qui analysent le rôle des femmes dans la pensée foucaldienne. Il conclut sur ce qu'il appelle le «foin du dualisme philosophique » (р. п13), en illustrant notamment la non-applicabilité, voire l'incompatibilité, des catégories “ traditionnelles »-homosexualité vs. hétérosexualité - dans le contexte des pratiques érotiques et poétiques de l'ancienne Grèce. Dans la troisième partie, Question(s) de désir, Olivier Renaut s'attaque alors à l'analyse de la pratique de la pédérastie, nœud central du travail aussi bien de Dover que de Foucault. En relevant plusieurs paradoxes, et tout en ajoutant une note de relativisation finale (p. I3I), ce chercheur démontre que “l'érotique induite dans la pédérastie nous renvoie à un principe d'activité lié au désir d'un savoir, et ne saurait cependant évacuer complètement [...] la relation sexuelle.» (p. I3o) Suit un article de Daniele Lorenzini, qui parle d'un sujet qui reste, ailleurs dans ce livre comme dans le travail de Foucault, relativement sous-traité, à savoir la notion de désir. S'il est vrai que cette notion n'est pas au centre de la pensée foucaldienne, elle n'en reste pas moins un élément indispensable, tout comme la notion et l'institution du mariage, sujet du premier article, de la main d'Arianna Sforzini, de la dernière partie intitulée Repenser les corps et les normes. Dans son étude, Arianna Sforzini montre que dans le premier christianisme la notion de pudeur n'en était qu'à ses débuts, tout aussi hésitants que peu manifestes, et qu'à cette époque, « loin d'être "sexophobe”, le christianisme donnait une place centrale à la sexualité dans la subjectivité occidentale» (p. i62). Cet ouvrage, qui a le mérite d'être vendu à un prix tout à fait modique, 
est conclu par un article plutôt technique de la main de Thamy Ayouch, qui prend pour objet et méthode la psychanalyse. Une étude qui illustre une fois de plus le grand potentiel pluridisciplinaire du travail de Foucault et des études foucaldiennes, devenues désormais une discipline à part.

Jan NELIS

Fondation de la Mémoire Contemporaine / Université libre de Bruxelles jnelis@ulb.ac.be

Corinne Bonnet, Nicole Belayche, Marlène Albert Llorca, Alexis Avdeeff, Francesco Massa, Iwo Slobodzianek (dir.), Puissances divines à l'épreuve du comparatisme. Constructions, variations et réseaux relationnels, Brepols, Turnhout, Bibliothèque de l'École

Pratique des Hautes Études en sciences religieuses (BEHE, I75), 20I7, 496 p., 70 €/ ISBN 9782503569444 .

Ce livre présente les contributions des deux colloques organisés, en mars et novembre 20I4, par les universités de Toulouse, d'Aix-Marseille, et l'École Pratique des Hautes Études (section des Sciences religieuses). Comme le précise l'introduction générale (p. 5-25), il a pour objet de commenter l'affirmation de J.-P. Vernant: “Les dieux helléniques sont des Puissances, non des personnes ", au regard de la recherche actuelle et dans une approche comparatiste. Les 2I contributions sont réparties en cinq sections, présentées chacune par une introduction qui souligne l'apport des auteurs à la thématique choisie. Les notions d'altérité, de structure, d'aspect, de qualité et de captation de la puissance divine sont étudiées successivement.

La première partie, intitulée «Des outils pour (dé)construire la puissance divine ", s'ouvre sur l'invitation d'A. Avdeeff (p. 29-3I) à situer la notion de puissance divine, dans le contexte historiographique et ethnographique des années ig6o. Les deux contributions qui suivent, soulignent la nécessité de rompre avec les modes de pensée hérités du christianisme et du "miracle grec». Afin d'éclairer la démarche intellectuelle de J.-P. Vernant, V. Pirenne-Delforge et J. Scheid (p.33-52) rappellent l'impact sur l'histoire des religions de la psychologie historique (Ignace Meyerson) et l'apport de l'école de sociologie, transmis par Louis Gernet du côté grec. G. Schlemmer cherche à tester la pertinence du panthéon grec, défini par J.-P. Vernant comme un système organisé, dans la société tribale des Kulung du Népal, sans discours sur la nature des esprits. Les notions grecques de système et de classification des dieux ne sont donc pas opératoires dans un tel milieu (p.53-66).

La seconde section porte sur la structuration et la plasticité des panthéons. Dans son introduction (p. 69-7I), I. Slobodzianek souligne que pour J.-P. Vernant, le panthéon grec est un système organisé où chaque dieu prend sens dans un ensemble général. Les auteurs démontrent que les panthéons répondent toujours à certaines normes en dépit de leur plasticité. Après avoir souligné que la Mésopotamie est “ une terre encombrée de divinités ", J.-J. Glassner retient trois figures de souveraineté divine en relation avec les villes: Enlil, dieu de Sumer, Marduk, dieu poliade de Babylone et Assur, dieu de la ville et du pays homonymes (p. 73-87). Ces grands dieux territoriaux, bien qu'en concurrence, sont tous inspirés de la cosmogonie babylonienne. Dans l'étude qui suit, G. Pironti interroge le polythéisme (p. 89-Io5) au regard d'une pluralité numérique, qualitative et dynamique. Dieux en famille, dieux en société, ne dessinent pas un ordre définitif mais plutôt des configurations recomposées en fonction du contexte ou du type de discours choisi. A. Avdeeff examine la pertinence de la notion de panthéon dans l'État du Tamil 
Nadu, en Inde du Sud, où l'astrologie et la divination jouent un rôle essentiel pour rendre les divinités locales plus accessibles (p. I07-I24). V. Zachari étudie la puissance divine au figuré en prenant pour exemple la représentation d'Apollon à l'autel sur les vases attiques (p. I25-I/3).

La troisième section traite des aspects personnels et relationnels de la puissance divine. A. Avdeeff précise en préambule (p. I47-I49), que les dieux grecs sont des figures singulières, dotées d'attributs significatifs de leur puissance. Par une étude linguistique (p. I5I-167), M. Bettini invite le lecteur à une réflexion sur la question du genre des puissances divines à Rome et du pluriel de leurs noms. À la lueur du travail de J.-P. Vernant, P. Pérez propose un essai sur la nature des Katsinam Hopi à travers les mythes et les rituels de la société amérindienne qui les a créés (p. I69I84). R. Naiweld choisit d'éclairer le dieu biblique par la médiation du culte judaïque des premiers siècles de notre ère (p. I85I99). La contribution de C. GuillaumePey nous entraîne dans le centre-est de l'Inde, chez les Sora (p. 20I-2I7), où les puissances topiques sont traitées comme des personnes dans “ un mouvement perpétuel de condensation-dilatation ». La dernière contribution de cette partie porte sur l'empereur Valens et sa relation à la puissance divine sous le christianisme (p. 2I9-233). C. Nicolas centre son étude sur la célébration de l'épiphanie à Césarée de Cappadoce.

La quatrième section, présentée par F. Massa, cherche à définir la qualité intrinsèque de la puissance divine. Partant du constat que J.-P. Vernant ne prend pas en compte les catégories d'omniscience et d'omnipotence, H. S. Versnel, auteur d'un ouvrage Coping with the Gods (20II), relève que certaines sources littéraires grecques des époques archaïque et classique, à savoir la littérature gnomique et le genre hymnique, font bien référence à ces notions. Pour I. Slobodzianek, la puissance divine est remise en cause dans les mythes relatifs à Aphrodite et Inanna. Ces déesses se voient, en effet, humiliées et réduites à l'impuissance. Toutefois, leur déshonneur ne remet pas en cause leur statut divin (p. 263-278). Le vocabulaire des émotions, étudié par C. Bertau-Courbières, trace une limite entre le monde des mortels et celui des dieux (p. 279-290). S. d'Intino pose la question de la nature des dieux dans les hymnes védiques (p. 29I-Io8). Les dieux n'ont pas de personnalité, ils sont labiles. "Cachés au fond du langage », ils sont au centre d'un système de relations entre plusieurs réalités: cosmique, rituelle et psychologique. R. Parker retient comme sujet d'étude les dédicaces adressées à une combinaison de dieux. Dans le monde gréco-romain au sens large, des noms de dieux sont en effet juxtaposés comme Zeus Dionysos ou Zeus Ammon. Quand un dieu a Zeus ajouté comme préfixe à son nom, ce que l'auteur appelle “Zeus plus», sa dignité en est accrue (p. 3og-32o). À la fin de cette partie, les papyrus magiques de l'Égypte gréco-romaine du début de notre ère sont questionnés par T. Galoppin pour démontrer comment la magie égyptienne “fait de la puissance » par la médiation du prêtre, maître de cérémonie (p. 32I-332).

La dernière section porte sur la captation des puissances divines et leurs liens avec les paysages religieux. Pour F. Massa qui présente cette thématique (p. 335-337), les contributions regroupées dans cette partie abordent la question de la délimitation de l'espace sacré et des rapports de force produits en ce lieu. O. Journet-Diallo, spécialiste des Jóola, une société africaine qui habite entre le Sénégal et la Guinée-Bissau, relève que ses membres croient en un dieu créateur, mais qu'ils invoquent plus souvent des puissances intermédiaires, à savoir les âmes du riz et des défunts (p. 339-353). Pour étudier le vocabulaire de l'architecture sacrée dans l'ancien Israël et le contexte levantin, F. Porzia confronte les données de l'épigraphie et celles de la Bible (p. 355-378). 
A.-C. Rendu Loisiel s'intéresse aux temples de la Mésopotamie ancienne qui, en dépit de leur monumentalité, ne sont pas indispensables à l'accomplissement des rituels (p. 379-39o). M. Carrin cherche à définir la puissance divine des figures gémellaires en pays Tulu (Inde du sud) (p. 39i-406). Les bhuta sont des démons inférieurs qui forment un panthéon de 3 oo puissances et n'ont besoin ni d'un sanctuaire ni d'un objet. Y. Volokhine qui clôt cette section, étudie la figuration frontale des visages et des yeux sur les bols et les miroirs égyptiens (p. 407-42I). Cette dernière contribution est bien venue car elle pose les questions sousjacentes à l'ensemble du volume sur l'altérité et la signification des convergences entre civilisations.

Un cahier de photographies en couleur (p. 425-438) complète la publication des actes. Des indices, rédigés par T. Galoppin, permettent de circuler dans ce livre d'une lecture agréable par sa structure et la clarté de son propos. Le comparatisme étendu à différentes cultures offre la possibilité de penser la fabrique du divin à la fois dans le polythéisme et le monothéisme. La distinction du corps et de l'âme n'est pas universelle; les dieux résident ou non dans leurs temples; leur toute puissance est parfois éphémère ; les configurations et les réseaux divins diffèrent d'une société à l'autre.

Cet ouvrage, conçu comme un hommage à la pensée de Jean-Pierre Vernant, “ maître libérateur », explore son héritage, l'interroge, l'infléchit, le critique et le relativise. Il illustre l'impulsion donnée, dans la seconde moitié $\mathrm{du} \mathrm{xx}^{\mathrm{e}}$ siècle, par toute l'équipe de chercheurs qui, avec Marcel Detienne et François Lissarrague, a fait sortir les dieux et les déesses des dictionnaires et des études littéraires où ils étaient confinés, pour leur donner vie sous le signe du pluriel et du relationnel.

Geneviève Hoffmann Université de Picardie Jules Verne genevieve.hoffmann@wanadoo.fr
Shane Butler (éd.), Deep Classics, Rethinking Classical Reception, New York, Bloomsbury, 2016, 347 p., \$94 (hardback) et $\$ 26,96$ (paperback) / ISBN 978I4774260527 et 978I/7742605ı.

Deep Classics, Rethinking Classical Reception est un livre issu d'un colloque tenu à l'université de Bristol en 20I4. Ce colloque part d'une idée originale de l'éditeur scientifique Shane Butler, qui introduit dans les reception studies le concept de profondeur (depth), qu'il lie intimement à la notion de temps, observant que cette dernière notion, "to be sure, is hardly the only abyss into which the deep classicist stares [...] But it is time, as already has been noted, that gives 'antiquity' its name. And that name should remind us that spatiotemporal 'tradition' is not just what happens to the past after the past, but an extension of the question of why the past, qua past, continues to compel our attention » (p. i5). Au centre de l'attention se trouve la possibilité/l'impossibilité de réellement connaître l'Antiquité dans toutes ses manifestations et permutations. Ainsi, plusieurs disciplines, de l'analyse littéraire à l'archéologie et l'histoire de l'art en passant par la linguistique (contribution de Katz sur “Etymological 'Alterity': Depths and Heights) » et même les queer studies (excellente contribution de Matzner), offrent au lecteur un kaléidoscope des différents domaines dans lesquels l'étude et la théorisation des reception studies deviennent de plus en plus monnaie courante.

C'est ici, à l'instant où le “lecteur » de l'Antiquité rencontre son objet, que veut agir Deep Classics, dont nous regrettons seulement que le "programme» ne soit jamais clairement établi, ni dans l'introduction, ni dans un chapitre conclusif, malheureusement absent. Cela dit, à la fin du dernier chapitre, Laura Jansen formule des réflexions qui font office d'épilogue, voire de teaser préfigurant la publication 
d'un prochain volume dans ce domaine prometteur. En outre, la réflexion suivante, formulée par Slaney, se rapproche en quelque sorte d'une définition programmatique : "Antiquity is a necessarily imaginary property invested in particular landscapes, in objects (such as sculpture), andin architecture (such as ruins) by an awareness on the part of the perceiving subject that these material phenomena possess a certain temporal density, an interiority predicated on occluded experience: a form of depth. „(p. 87). Les participants au colloque se sont en effet rassemblés, non pas autour d'une thématique ou méthodologie, mais plutôt autour d'une tentative et d'un espoir, celui de déconstruire à la fois les reception studies et l'Antiquité elle-même. Inévitablement cette ouverture et cette liberté mènent à une certaine incertitude face au sujet, mais c'est une incertitude pleinement assumée, qui se traduit notamment par des démarches comparatives, voire métaphoriques, qui peu à peu lèvent le voile sur le message principal de ce livre : celui des classical reception studies comme un champ de recherche qui engage et en même temps questionne l'Antiquité, ainsi que le présent et les siècles qui les séparent, dans une interaction constante, fluctuante et évolutive. C'est précisément cela la " profondeur » que l'ouvrage explore en intégrant régulièrement des concepts et idées empruntés à d'autres disciplines. Car la plupart des contributions, bien que rédigées par des chercheurs travaillant dans des départements de Classics, adoptent une perspective résolument et réellement pluridisciplinaire; c'est aussi ce qui fait la grande force de ce livre, qui ne tombe pas dans le piège, souvent très présent dans les études de réception, d'une focalisation exclusive sur les mondes littéraire et académique. En outre, la majorité des articles sont à la fois très imaginatifs et rédigés dans une prose frôlant la virtuosité littéraire, tout en étant solidement documentés. Couplé à une grande unité et cohésion entre les différents chapitres, ce dernier aspect est claire- ment le fruit de la qualité des débats qui ont eu lieu lors du colloque, ainsi que du travail d'édition entrepris par Butler - presque tous les contributeurs en témoignent dans leurs notes.

Nous l'avons dit, le défi que relève Deep Classics de focaliser " on the very pose by which the human present turns its attention to the distant past» (p. II2) et d'étudier "past and present brought together in a matter of perspective and depths and heights „ (p. I2I), est de taille. Inévitablement les auteurs ne fournissent pas toutes les réponses, le projet étant avant tout un incitateur et un work in progress qui a le mérite d'effectivement créer ce que Frampton caractérise de «salutary awareness » (p. I76). Ici s'impose la question de savoir si Deep Classics, Rethinking Classical Reception représente une nouvelle voie dans les reception studies. Cela reste à voir, mais vu la densité et la qualité des contributions, ainsi que l'enthousiasme des auteurs, nous penchons pour une réponse affirmative.

Jan NELIS

Fondation de la Mémoire Contemporaine / Université libre de Bruxelles jnelis@ulb.ac.be

\section{Zeynep Çelik, About Antiquities: Politics} of Archaeology in the Ottoman Empire, Austin, University of Texas Press, 2016, 268 р., \$27,95 / ISBN 978г4773іо6і8.

About antiquities is a comparative, crosscultural study regarding the history of archaeology, centred in the last years of the Ottoman Empire, focused on questions such as: who owns antiquity and what are the good and bad uses of antiquities. It surely is a worthy lecture, not only because the author of the book, Zeynep Çelik, is probably one of the scholars who better knows the topic, but also because, currently, the heritage's destructions by DAESH have 
increased the importance of the questions raised in the book.

The introduction (pp. I-II) points out the previous studies initiated by herself and other scholars, establishes the purpose of each book's chapter and comments on some problems found during the investigation: the dependency from the sources available explains the lack of details and the impossibility of pursuing further in several topics.

The first chapter (pp. I3-4I) is centred in a comparison, trying to settle the origin of the Imperial Museum in relation to the other great museums, such as the Louvre, the British Museum, the Berlin Museums and the Metropolitan Museum of Art in New York. The Çinili Kösk served as the original museum to display the palace's collection but, since I882, there was also a School of Fine Arts dedicated to art education and later the main building of the museum was built. Thanks to its main promoter, the local archaeologist Osman Hamdi (d. I9Io), the Imperial Museum managed to get positioned on the map. However, as Zeynep Çelik stresses, the Ottoman museum had many differences with these other major museums (pp. 22-26) which rely on "an ambiguous relationship with the public" (p. 4I). Trying to reconciliate Islam with national ancient history generated problems and tensions in the Empire that stands out in the particular concept, decisions and development adopted for the Museum.

Chapter 2 (pp. 43-64) analyses the Western negative reactions to the formation of the Imperial Museum. The Westerns referred that classical antiquities did not belong to the history and identity of the Ottoman Empire and the opposition to the project became particularly aggressive after the passing of the I884 law of antiquities (revised extendedly in 19o6), that changed the traditional partage of the antiquities found (between foreign archaeologist and the Ottoman Empire) to the absolute ownership of all discoveries by the state. Briefly mentioned by Zeynep Çelik (pp. 46-48) are the supporters of the Ottoman project, despite their arguments preceded the current debates regarding who owns antiquities and for what purposes. One of these supporters was the German philologist and Orientalist, F. Max Müller (d. I9ı).

Chapter 3 (pp. 65-93) deals with the visitors that attended the Imperial Museum. Zeynep Çelik refers to a series of foreign travels accounts, guidebooks, catalogues and even postcards (pp. 67-85), pointing out how, at the beginning, many tourists left Istanbul without having realised of the Imperial Museum's existence. Particularly interesting are the pages (pp. 86-93) dedicated to the local visitors, particularly school excursions of students, and the high concern at the Museum about the preservation of antiquities and the control over archaeological sites. Questions are well pointed out by the author: What was the impact of the displays in the locals and students? What seems clear is that the museum evolved "from its exclusively academic beginnings into a more inclusive educational institution, albeit never achieving the level of public outreach and reception that the Metropolitan enjoyed" (p. 93).

Chapter 4 (pp. 95-133) promises to be a closer look to the Ottoman perception of antiquities, but it is just a further account on those popular Ottoman periodicals, looking for references about the public reception of the museum's collection and archaeological sites. Zeynep Çelik shows up how the accounts were quite small and random when related to the history of ancient cities, but more elaborated in their descriptions. Following also the idea of comparison that surrounds the whole book, the author refers to the Ottoman playwright Abdülhak Hamid (d. 1937), who wrote a particular version of Sardanapal in I876 (published in I9I9). The comparison raised between both reception of the Assirian king (European and Ottoman) is quite interesting: meanwhile Lord Byron's 
Sardanapalus represents a decadent and exotic vision of Orient, Abdülhak Hamid's Sardanapal criticizes the authoritarianism of the Ottoman Sultans (pp. I29-133).

Chapter 5 (pp. I35-I73) focuses on archaeological sites, investigating photographs, reports and diaries of the excavations to point out the relationship between the three sets of actors: European archaeologists, Ottoman officers and local labourers. Colonialism and Orientalism always come through these pages. The chapter also focuses on the role of Ottoman archaeologists (Hormuzd Rassam, Osman Hamdi or Osgan Efendi), who "shared the overall visions of their foreign colleagues in their perception of the local people, thereby doing away with the Eastern-Western dichotomy, but making class difference and educational background more pronounced" (p. I58).

The sixth and last chapter (pp. I75-2I3) centres the attention on the archaeological settlements, stressing the differences between the areas for Western archaeologists and the "native" villages of the local workers, both living together, but separately. Several examples are considered: Palmyra (pp. I75-I78), Sardis (pp. I80-I87), and finally Nippur, analysing here the "archaeologist castle" (pp. I87-I98) and the "native village" (pp. I98-2i3), as the main example for the colonial division at the archaeological sites.

The epilogue titled "Enduring dilemmas" (pp. 2I5-22I) puts an end to the book, going back to the questions already mentioned in the introduction, particularly the debate of who owns antiquity and when to return the objects illegally obtained by Western museums.

The conclusion that the lector arises when finishing the book is that Ottomans developed at the end of the $\mathrm{xIx}^{\text {th }}$ century a new way of understanding pre-Islamic vestiges that shares some characteristics with the European's, but also differs in many aspects. It is not that antiquities were forgotten until that time, and then considered as valued, just thanks to the European influence; on the contrary, those vestiges that were already part of their identity and cultural tradition were reinterpreted to get new responses for a changing political and cultural context.

At the end, some questions remain without an answer and several topics could also have been further developed. For example, the foreign and own Turkish destruction and looting of antiquities (p. 122 or p. 126) or the key figure of Osman Hamdi. Concepts such as "Antiquarism", recently questioned and reformulated to include a much broader range of practices and categories of reception beyond the traditional European interest in antiquity, could have been useful to provide a framework, as, for example, the idea of reuse as a pre-musealization way of displaying, formulated by M. K. Wendy Shaw's Possessors and Possessed: Museums, Archaeology, and the Visualization ofHistory in the Late Ottoman Empire. (Berkeley/Los Angeles, California University Press, 2003).

About antiquities is a remarkable contribution, encouraging us to understand history from different perspectives. After the IWW, the Ottoman Empire was forced to disappear and this new Ottoman approach to antiquities disappeared. Thanks to the efforts of Zeynep Çelik we can recover it and challenge our actual concepts of archaeology and museum.

Jorge Elices Ocón

Universidade Federal de São Paulo, Brasil jorge.elices.ocon@gmail.com 
Franz Cumont, Comment la Belgique fut romanisée, éd. Xavier Deru et Germaine Leman-Delerive, Rome, Brepols, Bibliotheca Cumontiana. Scripta Maiora V, 20I7, I4I p., $65 €$ / ISBN 9789074461863.

Le volume édité par Xavier Deru (XD) et Germaine Leman-Delerive (GLM) s'inscrit dans l'entreprise de réédition complète des œuvres de Franz Cumont (I868-I947) sous le patronage de l'Academia Belgica et de l'Institut historique belge de Rome. Si l'ouvrage de Franz Cumont (FC), publié pour la première fois en I9I4 dans les Annales de la Société Royale d'Archéologie de Bruxelles, est fondateur dans la genèse de l'archéologie nationale belge, ce texte rédigé par celui qui fut plutôt un grand historien des religions est le dernier qu'il consacra à son pays natal.

Fallait-il rééditer un texte écrit il y a plus d'un siècle, à une époque où ni Tongres, ni Arlon, ni Tournai, ni aucune autre ville romaine n'étaient alors connues archéologiquement? Par sa qualité, sa grande précision et son approche critique, l'introduction rédigée par XD et GLM justifie à elle seule tout l'intérêt de cette entreprise. Les éditeurs parviennent à brosser un portrait vivant de l'historien : un savant belge en lien avec les sommités européennes, soucieux de ne pas s'en tenir aux sources littéraires, ouvert aux découvertes archéologiques récentes, quoique peu intéressé par les balbutiements de l'archéologie protohistorique en Belgique.

Le volume comporte une très riche introduction de 45 pages qui fait le point sur les sources historiques et archéologiques utilisées par FC, sur le degré de connaissance qu'il avait de l'archéologie locale, sur ses réseaux intellectuels, sur le contexte général dans lequel l'ouvrage de FC a été composé et sur la réception de son texte. Les éditeurs soulignent avec justesse toute l'influence du contexte contemporain dans cet essai que FC consacre à l'antiquité de son pays d'origine : la Belgique connaît alors un dynamisme économique et culturel qui l'incite à se pencher sur ses origines. De plus, la colonisation des puissances européennes et la germanisation de l'Alsace annexée lui fournissent des modèles contemporains pour penser la romanisation.

L'essai historique de FC (II7p.) est ensuite édité en indiquant la numérotation originelle des pages et des notes infrapaginales. Plutôt que de reprendre les clichés photographiques utilisés pour la première édition, les éditeurs fournissent un dossier entièrement renouvelé des figures prévues par FC: les lecteurs apprécieront cette plus-value bienvenue.

Une rubrique appelée « L’atelier de Franz Cumont » fait enfin l'inventaire exhaustif des annotations manuscrites apportées par FC sur son exemplaire personnel: si en l'occurrence ces commentaires ne bouleversent pas ici l'éclairage du texte, cet appendice, commun à l'ensemble des titres de la Bibliotheca Cumontiana, est précieux pour cerner au plus près le regard que l'auteur portait sur son travail.

Les éditeurs soulignent la vision aujourd'hui datée de la romanisation portée par un FC qui n'en retient que les aspects positifs (l'œuvre civilisatrice de Rome face à la barbarie) et surtout qui tend à l'expliquer avant tout par ses aspects économiques. XD et GLM soulignent avec finesse l'influence du libéralisme caractérisant les élites belges de la Belle Époque quand FC écrit que les negotiatores sont les "premiers citoyens et les pionniers de la romanisation » (p. 22) ou que ce sont la prospérité économique et le confort apportés par Rome qui ont détourné les Belges “des aventures guerrières » (p. 4I). Ils ont raison également de souligner les liens entre la vision de FC et celle de son contemporain M. Rostovtzeff. Les éditeurs s'étonnent qu'à la différence de T. Mommsen ou F. Haverfield, FC ait été un « oublié sur le banc des accusés de l'historiographie contemporaine » (p. xLv) ayant reproché au concept de romanisation de 
reposer sur « la suprématie et l'excellence de la civilisation romaine et la minoration ou la négation des peuples qui la reçoivent ou la subissent, ainsi que l'on concevait la domination des empires coloniaux du début du $\mathrm{xx}^{\mathrm{e}}$ s. » (p. xLviI). Ce reproche ne nous paraît pas complètement s'appliquer à FC qui s'attache à distinguer la romanisation de la Belgique des pratiques contemporaines, non sans mépris pour les populations colonisées toutefois : “Rome n’a pas pratiqué sous l'Empire la colonisation en masse; elle n'a pas, comme l'Europe moderne, envoyé au-delà des mers des millions de prolétaires qui ont occupé des continents. Elle n'a pas non plus, comme nous le faisons dans les régions tropicales, soumis à une infime minorité de fonctionnaires et d'agents une multitude inassimilable d'indigènes d'autres races » (p. 2I). Les éditeurs prolongent leur critique en déplorant la persistance de l'usage du concept de romanisation justement critiqué dans le monde anglo-saxon et, en France, notamment par P. Le Roux. Ils lui préfèrent les termes supposés plus neutres d'acculturation, hybridation, métissage ou créolisation (non moins dénués de biais idéologiques, à notre sens). Pourtant, ce terme commode nous semble pouvoir être conservé à partir du moment où on se contente de considérer la romanisation comme « un simple moment du temps, celui de la transformation à la fois lente, hétérogène et inégale des sociétés protohistoriques au contact des nouvelles réalités induites par la conquête italienne » (M. Reddé). Ce faisant, on se départit du souci d'évaluer le degré d'avancement de telle civilisation par rapport à telle autre, entreprise périlleuse et moralisante de dénigrement/réhabilitation (p.xxix), de surévaluer le caractère prémédité et « messianique » du " projet romain » (p. xLVII) ou de raisonner en termes de "résistance» (p. xLv) comme si la romanisation était une occupation.

Bien que cet essai historique demeure tout à fait marginal au regard du reste de la production ultérieure de $\mathrm{FC}$, sa réédition par XD et GLM rappelle à quel point la production scientifique de l'historien, y compris pour les plus renommés et pour les spécialistes des périodes anciennes, ne peut se détacher de l'influence du contexte intellectuel, politique et économique contemporain dans lequel il évolue. En cela, le volume V des Scripta Maiora de la Bibliotheca Cumontiana intéresse autant l'historiographie des provinces occidentales de l'Empire romain que l'histoire culturelle du début du $\mathrm{xx}^{\mathrm{e}}$ siècle et la genèse de l'archéologie nationale belge.

$$
\begin{array}{r}
\text { Vivien Barrière } \\
\text { Université de Cergy-Pontoise } \\
\text { vivien.barriere@u-cergy.fr }
\end{array}
$$

\section{Olivier Devillers et Breno Battistin Sebastiani (éd.), Sources et modèles des historiens anciens, Ausonius, Bordeaux, 20I8, 46o p., $25 €$ / ISBN 9782356ı32ıo9.}

L'ouvrage, issu de deux congrès, offre une (re)lecture des contextes et méthodes de rédaction des œuvres des historiens anciens, ainsi qu'une réflexion sur leur réception. L'objectif proposé est de ne plus concevoir uniquement ces sources comme informatives ou littéraires mais comme des témoins historiographiques: “d'une part le prédécesseur informe sur un événement (source), d'autre part, il est celui dont la narration d'un événement donne des idées sur la manière de raconter un autre événement (modèle) » (p. I4). 28 contributions agencées chronologiquement forment ce volume.

Sept articles portent sur la production grecque. A. Sheppard éclaire l'usage par les historiens du Iv ${ }^{\mathrm{e}}$ siècle av. J.-C. des épigrammes et inscriptions, depuis Hérodote et Thucydide jusqu'à Théopompe. Chr. Pébarthe pose la question de l'utilité de la subjectivité et de l'engage- 
ment assumés de Thucydide comme outils de réflexivité. Br. B. Sebastiani met en exergue le portrait de Nicias par Thucydide avec le propre échec militaire de ce dernier et aborde son écriture sous l'angle de l'ironie existentielle. G. Ottone jauge le poids des modèles sur le récit de Théopompe et montre que la nouveauté du projet historiographique reste liée à la partialité de l'auteur et à sa méthode. A. Tsakmakis prouve l'effacement progressif de la chance / accidentalité comme facteur causal dans l'écriture de l'histoire, notamment chez Théopompe. J. Thornton met en évidence que l'intertextualité entre Thucydide et Polybe n'est pas seulement érudite mais provient aussi d'analogies historiques et doit se décoder au regard des normes historiographiques, des contextes politiques et des objectifs propres aux deux auteurs.

Les historiens de l'époque romaine constituent une part importante du volume avec I4 contributions. A. Worley montre comment le modèle de la mutinerie proposé par Tacite est réemployé comme outil historiographique chez les auteurs postérieurs. P. P. Abreu Funari et R.S. Garraffoni proposent une synthèse de l'œuvre de Salluste à la lumière de ses positions politiques et de son rapport à l'historiographie. G. Vassiliades défend l'idée que le projet monographique innovant de Salluste sur la conjuration de Catilina s'inscrit dans le cadre d'une emulatio avec ses prédécesseurs et contemporains. G. Urso aborde le même épisode chez Diodore de Sicile et démontre la multiplicité de ses reconstructions, l'auteur grec lui attribuant une importance limitée. Fr. E. de Oliveira Sousa, par la lecture croisée de Tite-Live et Virgile, indique que les deux auteurs transcrivent le rôle nouveau joué par la religion dans la recherche de légitimité politique populaire individuelle. D. Pausch revient sur l'archéologie de Tite-Live et son rapport à ses prédécesseurs via la guerre contre les Sabins, montrant l'importance du Forum Romanum comme lieu de mémoire. E. Tola montre, à travers l'anecdote de César aux prises avec une tempête en Adriatique, que la stratégie poétique adoptée par Lucain permet de souligner le choc socio-politique que constitue la guerre civile. F. Duarte Joly aborde la thématique ambivalente de la loyauté de l'esclave chez Tite-Live et Tacite qui illustre une analyse morale et politique différentiée entre le cadre républicain et le cadre impérial. Toujours dans l'optique de la critique du Principat, Th. Strunk met en lumière le projet tacitéen de déconstruction publique de la propagande et de l'héritage historiographique augustéens. K. E. Shannon analyse l'intertexualité entre Tite-Live et Tacite à propos des prodiges liés à la crue du Tibre au regard du concept de mémoire culturelle. P. Duchêne revient sur le portrait d'Othon chez Plutarque, Tacite, Suétone, et Dion Cassius et identifie ses traits fixes ou flottants dans une perspective historiographique montrant la malléabilité d'un même épisode répondant à des stratégies narratives différentes. Chr. Baron prouve que l'intertextualité entre Hérodote et Arrien dans le livre 7 de l'Anabase permet à ce dernier de signifier les excès et limites des conquêtes d'Alexandre le Grand. Ch. Carsana montre que la mobilisation de sources par Appien au livre 2 des Guerres Civiles n'empêche pas l'auteur alexandrin de développer sa propre vision critique et historique des évènements. L. Ballesteros Pastor tente avec prudence d'identifier chez Dion Cassius les indices attestant que les Histoires de Salluste lui auraient servi de modèle critique et narratif.

Trois études portent leur attention sur la production de l'Antiquité tardive. M. Antiqueira montre que le bréviaire de Festus, concentré sur les événements frontaliers l'histoire romaine, peut se comprendre au regard du contexte oriental de son époque. A. M. Kemezis aborde les méthodes de l'Histoire Auguste qui, malgré ses scriptores et éléments fictifs, permet tout de même à l'auteur de développer sa vision de l'histoire romaine. A. J. Ross analyse le positionnement d'Ammien Marcelin vis-à-vis de la tradition historiographique et 
la hiérarchisation des références qu'il opère explicitement ou implicitement.

Deux articles abordent les historiens chrétiens. G. Ventura da Silva offre une réflexion sur l'hagiographie autour de l'epitaphios logos de Saint Jean Chrysostome et montre qu'au-delà de l'aspect apologétique, ce type d'œuvre peut comporter une réflexion de nature historique. L. M. Frenkel aborde la tradition de l'histoire ecclésiastique chez Théodoret de Cyr, qui, s'il s'inscrit dans la continuité des sources gréco-latines et tardives, réinterprète l'ensemble de l'histoire au prisme des conceptions chrétiennes.

Enfin deux contributions s'intéressent aux modèles anciens après l'Antiquité. Chr. T. Mallan analyse les travaux de Jean Zonaras et montre que le recours aux auteurs anciens ne relève pas d'une simple abréviation esthétique mais d'une réflexion historique et politique. G. Flamerie de Lachapelle illustre les échos de Florus dans le xviI ${ }^{\mathrm{e}}$ siècle français et révèle que sa convocation explicite, expliquée par le contexte historique et le projet historiographique, doit être nuancée. L'ouvrage est clôturé par une vaste bibliographie générale (p. 39I428), un index des œuvres citées et un index des noms.

O. Devillers et B. B. Sebastiani livrent ici un ouvrage exigeant mais accessible dont la lecture revêt un double intérêt. D'une part il renouvelle, sans épuiser totalement le sujet, l'approche des historiens anciens et de leurs écrits en les contextualisant dans les préoccupations de leur temps et en analysant leur rapport au passé. D'autre part, l'analyse des objectifs et des outils de nos prédécesseurs antiques contribue à éclairer notre propre façon d'écrire l'histoire. En conséquence, la lecture de ce volume rend les textes et leurs auteurs antiques plus vivants et plus actuels que jamais.

Arnaud Saura-Ziegelmeyer Université Toulouse - Jean Jaurès a.sauraziegelmeyer@gmail.com
Mara Fazio, Pierre Frantz et Vincenzo De SANTis (dir.), Les Arts du spectacle et la référence antique dans le théâtre européen (I760-I83o), Paris, Classiques Garnier, 20I8, 402 p., $37 €$ / ISBN 9782406066439.

Cet ouvrage est issu d'un colloque international portant le même titre qui s'est tenu en deux temps les i4 et i5 décembre 2012 à l'Université Paris Sorbonne et les 8 et 9 février 2013 à l'Università di Roma la Sapienza.Enintroduction M. Fazio,P. Frantz et V. De Santis soulèvent la problématique de l'utilisation dans certaines œuvres de sujets liés à l'Antiquité au théâtre qui se retrouvent, pour cette raison, catégorisées comme néoclassiques. $\mathrm{Au}$ contraire, l'ouvrage propose de montrer que cette utilisation n'est plus nécessairement synonyme de conservatisme dans le théâtre du xvIII $^{\mathrm{e}}$ siècle et que l'Antiquité permet de " penser le nouveau sur le mode du retour », accompagnant les évolutions du théâtre de son temps voire favorisant les changements de règles d'écriture. Les contributions de l'ouvrage sont réparties en trois parties: "dramaturgie et référence antique»; "l'Antiquité et la scène"; "chanter et danser l'Antiquité ». Une bibliographie thématique sélective de quatre pages est proposée en fin d'ouvrage ainsi qu'un index des noms propres.

La contribution proposée par R. BretVitoz présente le Spartacus de B.-J. Saurin (I76o) et l'utilisation du personnage afin de renouveler l'idéal du héros classique et lutter notamment contre le préjugé de naissance avec un héros de basse extraction, à la suite de l'esprit des Lumières. M. Delon revient en trois temps sur la Térentia de Diderot : après avoir comparé l'écriture du plan du philosophe et celle, classique, de la versification en alexandrin de Tronchin, il aborde la redirection de l'héroïsme masculin sur les personnages féminins puis la question de la désacralisation du serment antique. T. Julian évoque quant à lui l'usage paradoxal de l'Antiquité, à la fois rejetée et persistante, dans la construction des 
tragédies nationales à travers les œuvres de M.-J. Chénier et présente les différences et les points communs entre pièces à l'antique et pièces nationales. E. Bellot distingue plusieurs degrés de rapprochements entre l'Antiquité et la France révolutionnaire (I789-1799) dans différents genres où la métaphore devient "plus politique que poétique» et suit les évolutions de la période. S. Marchand propose le suivi des réécritures, de 1767 à I845, de Virginie, fable romaine tirée de Tite-Live, oscillant entre tragédie sentimentale et politique, entre drame privé et public. La contribution de M. Saint Martin approche le problème posé par l'imitation du théâtre antique: comment adapter la fable ancienne au public et aux règles dramatiques modernes, mais aussi comment définir puis appliquer l'esthétique “antique» appelée comme pierre de refondation. Le texte de M. Melai dresse le portrait du peuple romain dans la tragédie de la France post-révolutionnaire, alternant entre la plebs haïssable et stupide et le populus incarné et héroïque selon l'idéologie de l'auteur. Fr. Lecercle revient sur le sujet prisé de Médée avec les exemples de R. Glover (I76I) et J.-M.-B. Clément (I779) et sur l'inventivité du retour à l'Antiquité et notamment la mise en avant de l'idéologie maternelle. La réécriture porte aussi au fabuleux et à l'hybridation des genres comme le présente A. Fabiano via le Sémiramis de Gozzi (I786). B. Alfonzetti livre, elle, une approche thématique sur les représentations de la Grèce antique en Italie, notamment Sparte et Athènes, à l'époque impériale (I796-ı8ı3). G. Laudin aborde les usages, en particulier politiques et classico-romantiques, de l'Antiquité dans le théâtre allemand en décrivant de très nombreux exemples pris entre i76o et i83o.

Introduisant la deuxième partie, l'article de P. Frantz met sur le même plan théâtre national et à l'antique quant au traitement de la dimension visuelle du sujet. J. Razgonnikoff jauge l'évolution de la scénographie (décors et costumes) dans les représentations de J. Racine, en particulier Andromaque, Iphigénie en Aulide et Britannicus. V. De Santis se centre sur la représentation du modèle antique des Atrides, notamment chez N. Lemercier, Mely-Janin et A. Soumet et au regard du contexte politique de l'époque (I797-I822). G. Ambrus livre une véritable enquête historique autour de la relation chaotique entre L.-J. Chénier et J.-L. David, plus précisément autour du projet des Thermopyles. Toujours autour du modèle spartiate, M. Fazio présente la mise en scène picturale du Léonidas (I825) de M. Pichat proposée par le baron J. Taylor et P. Cicéri tout en évoquant son rapport avec l'actualité de la guerre d'indépendance grecque. L'utilisation de l'Antiquité et en particulier de la sculpture dans les réflexions sur les théories du jeu des acteurs et le parallélisme entre les arts est plus globalement mise en avant par la contribution de L. Marie. S. Bellavia aborde les réflexions sur l'idéal dramatique de Goethe à Weimar et, à l'intérieur, l'influence del'Antiquité grecque sur le poète allemand. Enfin, F. Moulin propose une relecture du paradoxe des références à l'Antiquité dans la production littéraire et architecturale de N. Ledoux : l'écriture classique protège l'innovation extrême de l'architecture qui voit s'effacer l'amphithéâtre antique.

La dernière partie, consacrée à l'opéra et au ballet, élargit les bornes chronologiques de l'ouvrage avec tout d'abord l'article de Fr. Lévy qui aborde, notamment à travers les exemples d'Achille in Sciro de P. Metastasio et A. Caldara (I736) et Gli Orazi i Curiazi d'A. Sografi et D. Cimarosa (I796), l'influence de la référence antique sur les décors et, dans une moindre mesure, sur la musique des opéras du $\mathrm{xvII}^{\mathrm{e}}$ siècle. A. Rostagno compare ensuite l'utilisation de la même référence antique à Sappho chez G. Pacini (I840) et Ch. Gounod (I85I) et replace leurs œuvres dans leur cadre national réciproque. M.-C. Schang analyse, à partir des réflexions d'A. Grétry dans ses Mémoires, le traitement des personnages antiques et le modèle construit par le compositeur, notamment dans Le jugement de Midas (I778), en réaction à celui de Chr. W. Glück. 
M. Stacca s'intéresse aux déclinaisons du topos du triomphe d'inspiration antique au regard du contexte politique et religieux de l'Italie se dirigeant vers son Risorgimento. Fl. Pappacena s'attache à évaluer les innovations techniques et chorégraphiques du Télémaque de P. Gardel (I79o) et Dauberval (I79I). Enfin c'est La Vestale de S. Viganò et G. Spontini (I8I8) qui est présentée par $\mathrm{Cl}$. Celi qui montre dans la construction chorégraphique l'équilibre entre référence antique et nécessités romantiques du moment.

Le lecteur tire de cette “juxtaposition » (p. Io) de contributions une somme extrêmement riche et des réflexions novatrices. Les créations d'Italie et de France servent de socle principal aux analyses, viennent ensuite celles d'Allemagne et, dans une moindre mesure, d'Angleterre. L'introduction, claire et accessible, gagnerait, en l'absence de conclusion générale, à développer les questionnements terminologiques afin de donner un peu plus de relief aux « convergences, similitudes qui apparaissent, mais aussi des différences, nationales ou liées à la singularité des trajets et des carrières » (p. Io) à la lecture des contributions individuelles. Pour exemple, la polysémie du terme classicisme, l'ambiguïté et la difficulté à classer les sujets « à l'antique » chez les Anciens ou les Modernes ne font l'objet d'aucun traitement spécifique, d'aucun renvoi historiographique, même en note, et chaque auteur propose (ou non) ses propres définitions. Exception faite de cet éparpillement épistémologique qui aurait donné plus de relief à un tout très foisonnant, l'ouvrage alterne avec pertinence entre études monographiques et analyses plus globales et comparatistes, entre périodes, entre styles et entre nations.

Arnaud SAURA-ZiEgELMEYER Université Toulouse - Jean Jaurès a.sauraziegelmeyer@gmail.com
Jérémy Guedu et Barbara MeAzzi (dir.), La culture fasciste entre latinité et méditerranéité (1880-1940), in Cahiers de la Méditerranée 95, 20I7, $20 €$ / ISSN o39593I7; disponible en ligne : https:// journals.openedition.org/cdlm/878I

En 20I7, les Cahiers de la Méditerranée ont publié sous forme de dossier les actes d'un colloque international tenu à l'Université Nice Sophia Antipolis les 26 et 27 novembre 2015. Ce dossier, maintenant en libre accès en ligne, recueille des recherches qui étudient le fascisme d'un point de vue transnational, à travers les idées de latinité et méditerranéité. En utilisant un imaginaire historique et géographique lié à l'Antiquité, ces deux notions expriment une “communauté imaginée (Anderson), une “tradition inventée » (Hobsbawm-Ranger), une identité culturelle très discutée en France et en Italie entre $\mathrm{xIx}^{\mathrm{e}}$ et $\mathrm{xx}^{\mathrm{e}}$ siècles. La publication de ces recherches s'inscrit ainsi dans une série de travaux qui, ces dernières années, ont étudié la dimension transnationale du fascisme et ses enjeux culturels franco-italiens (voir les œuvres publiées ou coordonnées, entre autres, par C. Poupault, S. Rey, J. Guedj, A. Giladi).

Les études sur la latinité présentées dans ce numéro des Cahiers peuvent être réparties entre celles qui se focalisent sur la culture française et celles qui analysent la culture italienne. D'abord, comme Olivier Forlin explique dans sa contribution (p. 209222), il est à noter que l'espace géopolitique où ces débats idéologiques se déroulent est la Méditerranée, la mer où l'Italie place ses ambitions impériales, en concurrence avec la France et la Grande Bretagne.

Du côté français, l'identité latine est utilisée à partir des débats de la fin du xix ${ }^{\mathrm{e}}$ siècle sur la décadence des nations latines face aux nations septentrionales. Sarah Al-Matary (p. I5-29) a recherché l'idée latine dans la littérature française de la III $^{\mathrm{e}}$ République, en analysant les œuvres des écrivains nationalistes qui parlent de « race latine » ou « médi- 
terranéenne ». Les majeurs promoteurs de cette latinité en France sont les membres du Félibrige comme Charles Maurras. Sarah Al-Matary, Christophe Poupault (p. 3I-45) et Olivier Dard (p. 59-7o) ont analysé l'utilisation nationaliste, catholique, antidémocratique et antiallemande de la latinité de la part du dirigeant de l'Action française. La Première guerre mondiale, avec l'intervention italienne aux côtés de l'Entente, marque la phase la plus évidente de la rhétorique des " sœurs latines » contraposées aux Allemands. Ensuite, comme l'a souligné Ralph Schor (p. 47-55), durant l'entre-deuxguerres les intellectuels français conservateurs et antidémocratiques soutiennent encore l'identité latine pour proposer le rapprochement franco-italien et pour défendre le régime fasciste italien. Entre eux, le cas de George Valois a été étudié par Emmanuel Mattiato (p. I5I-I7I). À partir de son engagement dans l'Action française, et ensuite par son activité de fondateur du "Faisceau », cet admirateur du fascisme italien promeut un " bloc latin » franco-italien contre la "barbarie » de l'Amérique, l'Allemagne et l'Union Soviétique. Jérémy Guedj (p. I73-I89) a montré comment l'identité latine fut partagée même par les juifs français conservateurs, qui voient en l'Italie fasciste un modèle d'intégration nationale des juifs et une société sans antisémitisme. Cette illusion disparaît après les lois antijuives fascistes de I938, alors que les antisémites italiens et français instrumentalisent l'identité latine pour en exclure les juifs, comme l'explique Nina Valbousquet (p. IgI208) dans sa contribution à propos de Paolo Orano et Camille Mallarmé.

Du côté italien, la latinité est le mythe au cœur du nationalisme et de l'idéologie fasciste. Simona Storchi (p. 7I-83) s'est focalisée sur l'histoire de l'art, en montrant que l'idée de latinité a influencé le retour à l'ordre et ensuite l'adhésion des artistes au régime fasciste. Ce ne sont pas seulement les artistes qui critiquent les avant-gardes à revendiquer l'identité latine, mais aussi les architectes rationalistes et même certains futuristes, comme l'a montré Jean-Philippe Bareil (p. 97-I05). Manuela Bertone (p. Iog-II8) a souligné que Mussolini exprime une utilisation politique de la latinité déjà pendant la Première guerre mondiale, en revendiquant l'identité ethnique (“stirpe », “razza») italique, latine et romaine des Italiens contre les « barbares » septentrionaux. Antonella Mauri (p. Iı9-137) a étudié comment les fascistes au pouvoir ont repris ce mythe nationaliste dans leur projet pédagogique totalitaire. Alessandra Tarquini (p. I39-I5o) explique que l'idéologie fasciste reprend systématiquement des symboles romains, et que le régime transforme l'urbanisme de la ville de Rome pour souligner son antiquité et se légitimer. Même les historiens contribuent à ce mythe de la romanité pour défendre le régime et son impérialisme. Dans le même temps, le régime utilise la latinité comme instrument de diplomatie culturelle à l'étranger : c'est le cas, étudié par Amotz Giladi (p. 85-95), du rôle de la Società Dante Alighieri en France.

Le point culminant du rapprochement franco-italien, et donc du succès de la rhétorique de la latinité, est représenté par l'accord Laval-Mussolini de janvier I935. Dans la même année, le début du rapprochement italo-allemand marque par contre le déclin de l'identité latine, qui s'efface définitivement avec l'agression italienne à la France en juin I940. Johann Chapoutot (p. 225-23i) explique que même l'Allemagne nazie utilise la latinité, dans la mesure où le mythe de la race aryenne théorise une origine nordique commune aux Grecs, Romains et Germains. L'alliance avec l'Allemagne pousse Mussolini, et ensuite les collaborationnistes français, à préférer le mythe aryen au mythe latin comme discours identitaire hégémonique.

Les recherches de ce dossier des Cahiers de la Méditerranée ont le mérite de reconstruire les différents enjeux culturels transnationaux de cette période, et de nous rappeler que l'histoire ancienne met en jeu 
les identités contemporaines et peut ainsi devenir un facteur idéologique.

Andrea Avalli

Università degli Studi di Genova Université de Picardie Jules Verne xba@hotmail.it

Marie-Laurence HaAck (éd.), avec la collaboration de Martin MiLLER, Les Étrusques au temps du fascisme et du nazisme, Bordeaux, Ausonius, 2016, 337 p., $25 € /$ ISBN 978-2-356I3-г56-o

Les Étrusques au temps du fascisme et du nazisme, édité par Marie-Laurence Haack avec la collaboration de Martin Miller, est unetrès belleédition, richeenimages, et avec une bibliographie finale très bien fournie. Ce livre pose entre autres la question, importante, de la damnatio memoriae concernant la réception de l'Antiquité par les régimes nazifascistes. Là où cette question est souvent, et certainement dans l'étude de la réception italienne de l'Antiquité, noyée par un focus incessant sur le travail d'antichisti individuels, le présent volume évite sciemment ce piège et offre plusieurs réponses (pas nécessairement convergentes) à cette problématique. C'est pourquoi nous focaliserons cette recension sur les première et troisième parties du livre, qui présentent des réflexions plus globales et donc plus utiles à un lecteur non initié.

Après une introduction complète et nuancée dédiée à la question de l'étruscologie pendant l'entre-deuxguerres, le livre s'ouvre sur une étude de Raffaella Della Vela, qui aborde un sujet éminemment politique. Son article sur l'educazione scolastica, qui applique des méthodologies historiques mais surtout sociologiques, traite aussi bien du fascisme que du nazisme, et montre de façon incisive comment la rhétorique fasciste telle que l'on pouvait la rencontrer dans le langage scolaire, littéraire et plus généralement symbolique, envahissait tout le champ social, avec une force et une ampleur jamais vues. Della Vela montre comment les renvois au passé, son instrumentalisation, " infiltrando nelle menti dei bambini e dei giovani idee che, sotto l'aspetto di essere innocue e slegate dai totalitarismi, tennero in vita, per molto tempo dopo la loro caduta, parte del loro costrutto ideologico ». Elle poursuit par une réflexion qui interroge non seulement l'utilisation fasciste de l'antiquité, mais aussi notre propre positionnement par rapport au passé : "Aldilà della riflessione sui rischi di una strumentalizzazione totalitaria del passato, l'analisi di quanto accaduto all'immagine degli Etruschi e degli Italici propone una sfida relativa alla potenzialità di queste culture per la formazione di una società pluralista ed al modo in cui questa immagine si vuol tramandare alle future generazioni. „ (p. 66). Dans la suite, après une étude de Jean-Paul Thuillier sur le sport étrusque, sujet hautement pertinent au vu de l'intérêt porté par les nazifascistes au concept de virilité, et peu connu notamment à cause du manque de sources, et une autre étude sur la présence des Étrusques dans la pensée d'Alfred Rosenberg, auteur du Mythus des 2o.Jahrhunderts dont l'importance est ici soulignée (p. 92-93), l'article de Marie-Laurence Haack mérite que l'on s'y attarde car il aborde un sujet “ osé »: la race et la " raciologie ». En effet, si dans les reception studies dédiées à la réception italienne de l'Antiquité, le racisme, malgré son omniprésence dans l'Italie fasciste, est quasiment absent, la situation n'est pas bien meilleure pour ce qui est de la réception par les nazis. À ceci, Haack répond par une analyse du travail du médecin généticien Eugen Fischer, point de départ d'une discussion qui montre la pluralité des positionnements dans le “débat sur les origines ". 
Comme nous le disions, la deuxième partie du volume ne fera pas l'objet de cette recension; soulignons tout de même le fait que les quatre études qui constituent ce volet sont très bien documentées, et qu'elles font en quelque sorte office de charnière entre les sections I et 3. Cette dernière commence par des études sur la linguistique étrusque en Autriche/Allemagne (art. de Belfiore) et en Italie (art. de Benelli) en I928-ı942, période de consensus maximal avec les régimes nazifascistes. C'est dans l'étude de Benelli qu'un débat intéressant est introduit, qui touche à la profondeur de la fascistizzazione, de la "fascisation ». Benelli penche clairement pour la thèse de la superficialité de ce dernier phénomène quand il rapproche l'essence de l'utilisation fasciste de l'Antiquité, la fascisation, et donc le fascisme, à des effets de slogan en parlant de l'archéologie fasciste (qui n'est par ailleurs pas le sujet de l'article) : "In questa situazione si può capire come mai [...], se in Italia vi furono senz'altro un certo numero di archeologi fascisti, solo con qualche difficoltà si potrebbe individuare un'archeologia fascista, al di là dei generici slogan propagandistici sulla grandezza della romanità. » (p. 229). Ainsi la question de l'efficacité et du degré d'intériorisation de la rhétorique fasciste est posée, question qui ces dernières années a fait l'objet d'un débat qui touche à l'essence de ce qu'est le fascisme, voire l'extrême droite. Dans ce cadre, la réduction d'une idéologie politique ayant connu un succès fulgurant pendant les années I920 et I93o à des effets de rhétorique nous semble quelque peu sous-estimer l'une des principales caractéristiques du fascisme, à savoir son essence théâtrale, pour ne pas dire cultique - pensons ici au phénomène de "religion politique» développé notamment par Emilio Gentile. Car la parole fasciste, qui inclut le langage propagandiste, symbolique et les slogans, est une source essentielle pour connaître sa vraie nature et ses intentions. Ces aspects sont traités de façon incisive dans la dernière étude que nous souhaitons relever, de Giuseppe Pucci, sur art étrusque et idéologie. Dans son article, Pucci montre avant tout que pendant l'entre-deuxguerres le passé antique faisait l'objet d'un débat, d'une négociation entre différents secteurs de la société, une négociation qui en soi n'était pas fort différente de celles qui ont lieu aujourd'hui, entre passé et présent, et entre différentes idéologies. Dans ce contexte, l'étruscologie bénéficiait pendant un certain temps d'un intérêt général pour l'antiquité, pour finalement en payer les frais. Car, en effet, il s'agissait d'un dialogue " qui, au cours des années vingt et trente, s'établit en Italie au sujet des Étrusques entre artistes, archéologues et idéologues (notamment les idéologues de la race), et [...] alla se heurter à des difficultés croissantes, jusqu'à devenir décidément embarrassant, puis finalement inactuel. (p. 24I). Un dernier mot, comme il est question ici de dialogue: notre seul véritable regret, dans ce bel et important volume dont nous recommandons chaleureusement la lecture, est la quasi absence de la littérature secondaire anglosaxonne.

Jan NELIS

Fondation de la Mémoire Contemporaine / Université libre de Bruxelles jnelis@ulb.ac.be

Arlene Holmes-Henderson, Steven

Hunt et Mai Musié (éd.), Forward with Classics. ClassicalLanguages in

Schools and Communities, Londres et Oxford, Bloomsbury, 2018, 296 p., £95 /

ISBN 9781474295956.

Forward with Classics représente l'aboutissement de deux cycles de conférences organisées à Oxford en 2013 et à Cambridge en 2015 dans le cadre du projet “Classics in Communities " qui vise à revivifier l'enseignement des Classics : ces 
conférences ont porté sur la question de la diffusion de l'enseignement des langues anciennes auprès d'un public le plus large possible. De ce fait, si le premier public auquel on pense pour un tel ouvrage est celui des enseignants de latin et de grec, quiconque s'intéresse à la question de la place à accorder à ces disciplines dans la formation intellectuelle y trouvera de quoi alimenter substantiellement ses réflexions.

Après un avant-propos de Mary Beard tout en malice et en optimisme au sujet de l'avenir de cet enseignement, et une introduction des trois éditeurs présentant le projet "Classics in Communities", les dix-sept contributions sont organisées en trois parties. La première partie décrit quels sont le cadre politique et la place de l'enseignement des Classics au RoyaumeUni, dans le reste de l'Europe, en Australie, au Brésil et aux États-Unis. La seconde est constituée d'études de cas, remarquables notamment par la variété des situations et des publics envisagés, des écoles primaires britanniques aux prisons sud-africaines. La troisième partie, enfin, envisage les moyens d'assurer l'avenir des Classics: apports des nouvelles technologies dans l'enseignement, analyse de l'employabilité des jeunes gens formés aux Classics. La conclusion établit un bilan de tout ce qu'a permis le projet Classics in Communities, sans éluder les difficultés ni les questions qui demeurent en suspens.

Le recul indéniable de l'enseignement des Classics pousse les enseignants qui souhaitent continuer à faire vivre leur discipline à une réflexion particulièrement approfondie et renouvelée, au sujet de sa légitimité et de ses objectifs. La baisse drastique des effectifs, déjà bien installée depuis plusieurs décennies, est l'occasion de s'interroger sur ce qui rend la connaissance des langues et des civilisations de l'Antiquité si précieuse, et, dans le même temps, d'affronter radicalement les obstacles qui limitent sa diffusion. S'il est d'usage de s'alarmer devant la disparition presque accomplie de l'enseignement des Classics, ces contributions entendent inciter à un optimisme certain en montrant qu'il est possible de mettre en place des actions propres à favoriser son retour. Forward with Classics permet d'établir des constats clairs en ce qui concerne les obstacles susceptibles de s'y opposer, et propose des pistes tout à fait concrètes permettant de les surmonter. Les projets et les expérimentations qui sont rapportés mettent en avant l'apport des Classics dans un enseignement qui se veut profondément humaniste : faire comprendre leur actualité, c'est, en fait, rappeler leur éternité et leur universalité dans un discours audible pour les élèves, les étudiants, les parents, les acteurs politiques d'aujourd'hui. Loin de vouloir promouvoir leur enseignement comme un moyen de sélection silencieuse de l'élite, les contributeurs ont à cœur d'en faire bénéficier un public aussi large que possible, forts de la conviction que le goût de ce qui a trait à l'Antiquité est toujours bien vivace et qu'il ne demande qu'à être stimulé.

Bien qu'au terme de la lecture de l'ouvrage il paraisse difficile de discerner une ligne générale, il faut noter un certain parti pris dominant en faveur d'un renouvellement des méthodes d'enseignement: l'on ne trouvera pas ici de défense de l'enseignement “traditionnel » du latin ou du grec, orienté vers l'apprentissage systématique de la grammaire et l'exercice de la version. Si l'incitation à communiquer à propos des nouvelles méthodes d'enseignement (telles que la «méthode directe ») constitue un mot d'ordre commun (en l'absence de soutien institutionnel fort, on ne peut plus continuer à enseigner les Classics qu'à condition de rallier un public volontaire et motivé), les objectifs des contributeurs sont très divers : tandis que certains vont concentrer leurs efforts en direction du renforcement des compétences linguistiques (meilleure maîtrise de la langue maternelle par l'étude de ses racines 
latines et facilitation de l'acquisition des langues étrangères), d'autres vont mettre l'accent sur les apports culturels, et certains vont même se contenter de l'idée d'éveiller un intérêt pour l'Antiquité classique. On voit bien ici qu'il est question, non pas de l'enseignement du latin et du grec, mais bien des Classics dans toute la diversité des disciplines que le terme recouvre.

Pour le lectorat français, certaines contributions peuvent susciter des questions. L'enseignement dans les pays anglo-saxons apparaît comme bien moins centralisé que l'enseignement français, au sein duquel programmes et horaires disciplinaires assurent un cadre général. Notre système est aussi probablement moins souple: nous n'avons pas de tradition très ancrée de la pratique des clubs hors temps scolaire, alors que plusieurs contributions rapportent que ceux-ci peuvent constituer une première voie d'entrée du latin dans un établissement qui n'en propose pas. Le rôle de financements extérieurs (via par exemple la fondation Classics for All) paraît crucial pour pallier une absence de volonté gouvernementale: il n'existe rien de comparable en France. Enfin, le développement actuel de l'enseignement des Classics au Royaume-Uni par des enseignants non spécialistes, qui peuvent même découvrir le latin ou le grec en même temps qu'ils l'apprennent à des élèves, dans un contexte de pénurie d'enseignants spécialistes, peut surprendre.

Plus généralement, nombre de contributions soulignent l'importance des volontés individuelles, ce qui implique une certaine fragilité des projets décrits, d'ailleurs évoquée ouvertement à plusieurs reprises. Les problèmes de financement constituent également une menace vis-à-vis de leur pérennisation. Face à ces difficultés, la collaboration entre établissements primaires, secondaires et supérieurs apparaît aux contributeurs comme une nécessité, mais, en fin de compte, l'on finit par se demander si réellement la détermination, l'énergie et la créativité des enseignants sont toujours suffisantes pour pallier les effets délétères de certains choix politiques à grande échelle.

Par ailleurs, on retrouve dans beaucoup de contributions ce qui est à la fois un avantage et un inconvénient des retours d'expériences d'enseignement: les situations décrites, extrêmement diverses, on l'a dit, sont particulières à un contexte, et les auteurs sont à la fois juges et parties, ce qui peut rendre difficile l'évaluation objective des résultats obtenus. Néanmoins, les contributions en question apportent des données tout à fait concrètes et toujours soigneusement contextualisées, et l'ensemble offre au lecteur la possibilité de prendre et de laisser ce qu'il y trouve selon ses convictions et la situation qui est la sienne.

Charlotte TourniER

Sorbonne Université / Université de Lille tournier.charlotte@yahoo.com

Daniel Jew, Robin Osborne et Michael

Scotт (éd.), M. I. Finley. An Ancient

Historian and his Impact, Cambridge, Cambridge University Press, 2016, 333 p., \$99,99/ ISBN 978IIo7I49267.

En 20I4, Anabases a publié un imposant dossier sur « Moses I. Finley (I9I2-I986) et sa réception en France », issu pour l'essentiel d'un colloque organisé à Paris en décembre 20I2. Avec le présent livre, qui rassemble des contributions à un colloque organisé à Cambridge au mois de mai de la même année, on passe de l'étude de la réception dans un pays particulier à la réflexion sur l'impact que la personne et l'œuvre de Finley ont eu sur la recherche en histoire ancienne et sur l'enseignement de l'histoire ancienne. Sur la couverture du livre, la notion d'impact est-ironiquement? -illustrée par un " camembert » dont les tranches de différentes couleurs et épaisseurs 
représentent les proportions des citations, dans des revues majoritairement de langue anglaise, des travaux majeurs de Finley, telles que les mesure un très sérieux citation index. Que l'on se rassure: dans le quinzième et dernier (très court) chapitre, Walter Scheidel a rassemblé des statistiques qui montrent, sans véritable surprise, que dans la période après 1975 Finley figure dans le peloton de tête des antiquisants les plus fréquemment cités et que The Ancient Economy est son livre le plus cité. Scheidel commence sa présentation par une défense de ce type de mesure d'impact et la termine en citant Finley lui-même qui, en I985, répondant à une question posée par Keith Hopkins, avait évalué son propre “ impact » sur l'histoire ancienne en ces termes: "... there is now an increasing number of ancient historians who do more of what I call proper historical writing. » (p. 297). Scheidel conclut, réaliste, que si l'impact de Finley a consisté à modifier la pratique de l'histoire, ce n'est pas un citation index qui peut en apporter la démonstration, mais uniquement un "careful engagement with the scholarly literature ».

C'est ce qui est réalisé parfaitement dans ce livre, et non seulement cela. À le lire d'un bout à l'autre, le lecteur (et notamment celui qui n'a ni connu Finley personnellement ni fait l'expérience d'un séjour de recherche à Cambridge) se voit plongé dans un univers académique bien différent de l'université française; il est confronté à des témoignages et des appréciations très vivants et plastiques de la personnalité de cet immigré américain qui, nourri de sociologie, a bousculé l'enseignement très traditionnel des études classiques, en y introduisant non seulement l'histoire économique et sociale, mais surtout des questionnements et méthodes novateurs. On apprend comment Finley a construit des réseaux scientifiques internationaux dans lesquels il fait circuler ses "élèves ». On le voit intervenir dans la presse, télévision et surtout la radio, s'engager dans la réforme de l'enseignement de l'histoire dans le secondaire. Particulièrement intéressants sont les témoignages sur sa façon de guider et solliciter ses étudiants, doctorants ou jeunes collègues dont certains, comme par exemple Quentin Skinner, sont loin de l'histoire ancienne.

La question de l'impact est déclinée de manières diverses dans les différents chapitres. Les auteurs ne se contentent pas de recenser les recensions des publications de Finley. Ils analysent les forces et les faiblesses de ses travaux et examinent de quelle façon ses intuitions et approches ont été poursuivis ou non après sa mort. Paul Cartledge (“Finley’s Democracy: A Study in Reception (and Non Reception) ") observe même la "reception by Finley himself » qui se manifeste dans les grandes différences entre les première (I973) et deuxième (I985) éditions de Democracy Ancient andModern.

Signalons surtout aussi les études de Paul Millet sur Land and Credit in Ancient Athens, celle de Kostas Vlassopoulos sur "Finley's Slavery», ainsi que celle de Robin Osborne sur The World of Odysseus. Ce sont à la fois des études de l'impact et des relectures, souvent critiques, des œuvres elles-mêmes. Le chapitre consacré par Alessandro Launaro à The Ancient Economy est en lui-même une démonstration en force de l'effet stimulant que la réflexion inaboutie et souvent mal interprétée comme “primitiviste»-de Finley sur l'économie antique peut avoir dans un dialogue entre historiens d'époques prémodernes et économistes inspirés des New Institutional Economics. L'empreinte laissée par Finley sur l'enseignement est étudiée par Dorothy J. Thompson, celle sur l'Université de Cambridge par Geoffrey Lloyd, l'impact sur un public plus large par Mary Beard (“Finley's Journalism»). La sociabilité du couple Finley et les rapports - amicaux, conflictuels, polémiques - entre Finley et ses collègues apparaissent notamment dans le chapitre sur Cambridge, dans l'étude du couple scientifique et amical formé 
par Moses Finley et Arnaldo Momigliano (Peter Garnsey), et également dans l'étude du rapport complexe - très critique voire polémique dans ses publications, toujours constructif dans la politique universitaire qu'entretenait l'historien avec l'archéologie et les archéologues (Jennifer Gates-Foster). Plus des deux tiers des auteurs ont ou avaient un lien direct avec l'Université de Cambridge. C'est aussi le cas de Wilfried Nippel (Berlin) que les insulaires ont chargé de la tâche d'évaluer l'impact de Finley sur le "Continent ». Il se limite, en fait, au cas italiens et français et attire l'attention sur le fait paradoxal qu'en Allemagne ne s'est trouvé personne qui - à la manière de ce qu'a su faire Pierre Vidal-Naquet en France - aurait pu établir un véritable lien entre la recherche allemande et Moses Finley qui - pourtant - représentait largement une tradition savante allemande, oubliée en grande partie dans ce pays. Que Finley soit consacré champion dans le citation index n'empêche pas que dans certains cas son influence sur la recherche ultérieure soit très limitée. Jonathan R.W. Prag le montre dans son étude sur le livre de ig68 History of Sicily: Ancient Sicily to the Arab Conquest, considéré comme " popular » et dépassé par la recherche ultérieure. C'est en relisant Finley, dit Prag, que l'on se rend compte de la justesse de beaucoup de ses jugements et observations, "but no one reads him a second time». Ce constat pessimiste risque, heureusement, d'être invalidé par les lecteurs de ce passionnant ouvrage sur un historien qui a changé la pratique et l'image de l'histoire ancienne.

Hinnerk BRUHNS CNRS / EHESS, Centre de recherches historiques bruhns@ehess.fr
Kostas Kalimtzis, An inquiry into the philosophical concept of scholê. Leisure as a Political End, Londres et Oxford, Bloomsbury, 20I7, 227 p., $£ 90$ (hardback) et $£ 28,99$ (paperback) /

ISBN 9781474237932 et 9781350079878.

Kostas Kalimtzis s'adresse à un public curieux d'approfondir sa compréhension de la philosophie antique, en l'abordant à travers le prisme de la scholê. L'auteur propose une enquête répondant à un double questionnement: dans quelle mesure la schole, comprise comme le temps libre ou loisir consacré à l'activité théorétique, peutelle devenir la fin collective de l'activité politique, et comment ce concept a-t-il pu se transformer, au point de ne pouvoir être rendu que par le mot loisir, ne présupposant plus aucune activité intellectuelle?

Si l'ascholia est ce qui est privé de scholê, l'activité qu'entraîne un esprit toujours affairé, comme l'illustre le mythe de Sisyphe, dans le Chapitre I, la scholê n'est pas pour autant synonyme d'oisiveté, comme en témoigne le verbe grec scholazo. La scholê est une action: soit le loisir, comme moyen, consacré à la recherche de la vérité, non dépourvu de tourments, comme il est démontré dans le Chapitre 2 ; soit la fin de ce processus, atteint dans la possession du bonheur liée à la contemplation de la vérité. La scholê apparaît comme un processus cathartique, décrit dans le Chapitre 3, par lequel l'homme tourmenté par la recherche de la vérité n'obtient la scholê, comprise comme la tranquillité de l'âme, que dès lors qu'il contemple la vérité désirée. Si la catharsis peut passer par la dialectique faisant émerger la vérité, elle peut aussi être obtenue par la mimesis, l'imitation des actions vertueuses, mise en œuvre par et dans le jeu théâtral, au centre de l'éducation des citoyens décrite par la Platon dans la République. Le théâtre est une activité en accord avec le nous visant à créer des citoyens vertueux, ce qui n'est qu'une propédeutique à l'activité du nous : 
la vie théorétique étant comprise comme la véritable fin de toute vie humaine. Toutefois, Platon semble pessimiste quant à la possibilité de créer une cité de philosophes, réservant l'activité théorétique à une minorité d'âmes d'or, d'élus.

Le Chapitre 4 met en lumière la spécificité de la pensée aristotélicienne, qui loin de réserver la scholê à une élite, la conçoit comme une puissance de la cité qui ne peut être actualisée que dans la mesure où les citoyens la choisissent collectivement comme fin de la cité, lui conférant ainsi une dimension éminemment politique. Cependant, pourquoi la choisiraient-ils comme fin de l'activité politique et comment parviendraient-ils à la rendre possible? Kalimtzis traite cette difficulté dans le Chapitre 5, en insistant sur l'originalité de la pensée d'Aristote, qui met au centre de sa réflexion le rôle de la musique comme moyen pour actualiser la scholê, que tout homme conformément à sa nature intellective devrait choisir comme fin. La musique est un bien qui ne peut être obtenu que collectivement, en la choisissant et en organisant conformément à ce choix sa production. Le loisir consacré à la musique (diagogè) prépare les citoyens à choisir la scholê collectivement et à l'unanimité (homonoia) en créant les conditions nécessaires à sa réalisation : c'est-à-dire, d'une part, en mettant à la disposition de tous les citoyens les ressources nécessaires à une vie dont le travail est exclu, ce qui a valu à Aristote ses plus vives critiques, concernant sa bienveillance vis-à-vis de l'esclavage, et d'autre part, en instaurant une éducation propre à développer les vertus morales et intellectuelles de l'enfant, faisant de la justice un moyen au service de l'activité théorétique, véritable fin de la cité.

Le Chapitre 6 met en lumière la progressive transformation du concept de scholê devenue inopérant dans un monde duquel la liberté politique est absente. En lien avec la création de l'école d'Alexandrie, consacrée aux travaux spéculatifs, et avec l'enseignement des Stoïciens, la scholê est progressivement réduite à l'école, alors qu'à Rome où le concept de scholê est absent, c'est l'otium qui donne lieu à une réflexion sur la fonction morale et politique du loisir. Dans un premier temps, Cicéron le définit comme l'activité publique ou privée ayant pour but de favoriser la paix, puis dans un second temps, avec l'apparition du Principat, il est conçu comme la liberté ou la contrainte de se retirer des affaires publiques pour mener une existence privée, dont le sage, à l'instar de Sénèque, sait se saisir pour contribuer, par son exemple et son enseignement, au bien de l'humanité, à moins qu'il ne profite de ce loisir pour mener une vie de plaisirs et de dissipations. L'ambivalence de l'otium, moyen favorisant l'exercice des vertus privées et publiques et source de corruption, devient, avec les Pères de l'Église, sous le terme de scholê, amputé de sa dimension politique et théorétique, un concept d'abord discuté pour cette même ambivalence, puis abandonné au profit de la prière. Elle lui est préférée comme activité de contention de l'esprit propre à conduire à la contemplation de Dieu, celle-ci se substituant à celle de la vérité.

Pour Kostas Kalimtzis, le concept de scholê doit être remis au cœur de la pensée philosophique et politique pour répondre au besoin ressenti, de plus en plus vivement, de proposer un autre mode de vie que celui lié à l'activité permanente, valorisé par la société de consommation. L'index (p. 223227) permet de retrouver aisément les références et concepts contextualisés et explicités de manière très approfondie dans les notes proposées à la fin de l'ouvrage (p. I8I-2Io), assorties d'une bibliographie très complète sur le sujet.

Florent RouzADE LGT Pardailhan, Auch florent.rouzade@gmail.com 
Anne-Hélène Klinger-Dollé,

Le De sensu de Charles de Bovelles.

Conception philosophique des sens et

figuration de la pensée. Suivi du texte latin

$d u$ De sensu, traduit et annoté, Genève,

Droz, Travaux d'Humanisme et de

Renaissance $\mathrm{n}^{\circ}$ DLVII, 20I6, 88г p., $89 € /$

ISBN : 978-2-6oo-oI865-4

Cet ouvrage remarquable, issu d'une thèse de doctorat soutenue en 2006, s'impose tant par l'ampleur du sujet traité, l'abondance et la richesse des textes étudiés que par la finesse des analyses philosophiques, littéraires et iconographiques et par la précision et la rigueur de l'érudition qui s'y déploie. L'auteure présente son livre comme « une invitation à [l]a découverte et à [l]a lecture » de Charles de Bovelles, philosophe et scientifique français de la première moitié du XvI ${ }^{\mathrm{e}}$ siècle, “ grâce à de larges citations traduites et commentées, grâce aussi à l'édition et à la traduction intégrale [du] traité De sensu » (p. I4), publié en I5ı dans un vaste recueil philosophique. Loin de se limiter à ce seul traité, A.-H. Klinger-Dollé analyse de nombreux textes de Bovelles, plusieurs autres traités, philosophiques, mathématiques ou théologiques, ainsi que sa correspondance. C'est un travail d'autant plus considérable, louable et utile que demeure " le manque encore criant d'éditions et de traductions modernes" (p. 20). Elle ne néglige pas non plus les textes d'autres humanistes de la même époque que Bovelles a côtoyés (Jacques Lefevre d'Etaples, Josse Clichtove ou Nicolas Bérauld par exemple) ou les œuvres des penseurs dont il s'est inspiré, d'Hugues de Saint Victor à Marsile Ficin, en passant par Raymond Lulle et Nicolas de Cues.

Le travail s'articule en deux grandes parties : les 35 o premières pages constituent bien plus qu'une vaste introduction : il s'agit d'une véritable monographie sur Bovelles qui met en lumière les lignes de force de sa pensée philosophique. La seconde moitié de l'ouvrage offre au lecteur le texte latin du De sensu, traduit et annoté, avec reproduction des figures et transcription des tableaux et schémas.

La première partie de l'étude permet de situer Bovelles dans le cercle des élèves et disciples de Jacques Lefevre d'Etaples avec lequel il entretient une relation intellectuelle et amicale. De nombreux passages de la correspondance y sont présentés, traduits et analysés pour faire apparaître les liens intellectuels et amicaux avec le cercle fabriste, car « la correspondance joue un rôle de stimulation intellectuelle, de partage spirituel et de manifestation essentielle de l'amitié » (p. 88). Le chapitre V interroge d'ailleurs les raisons de la rupture de Bovelles avec ce cercle dans les années i527-I528.

La deuxième partie montre combien Bovelles réalise une œuvre pédagogique: il s'agit de faire apparaître " à la fois l'intention pédagogique de Bovelles et son indépendance à l'égard des limitations habituelles des travaux de cet ordre » (p. I8). Menée à partir des œuvres philosophiques publiées en i5ı et du traité plus tardif $D e$ animae immortalitate, l'analyse fait ressortir la méthode de Bovelles et ses moyens : la pratique de l'analogie (p. I40), une pensée qui « progresse par oppositions » (p. I44), une exploitation des potentialités pédagogiques du genre littéraire du dialogue (p. I58) ou encore l'utilisation des représentations figurées pour une transmission plus claire et plus fluide des connaissances (p. I69). Bovelles offre ainsi à ses lecteurs " une œuvre qui allie ambitions spéculatives et préoccupations pédagogiques, intérêt pour la culture scolaire, universitaire, pour les traditions antiques et médiévales, tout en cultivant une forme d'indépendance à l'égard des autorités et des contraintes institutionnelles »(p. г76).

La troisième partie présente la notion de “médiations sensibles» (media sensibilia) du De sensu en développant les deux médiations essentielles que sont la parole et l'écriture. Le traité offre en effet une 
réhabilitation des sens et du corps humain (p. I83). “Le corps du traité démontre de surcroît la nécessité de recourir aux sens pour acquérir et transmettre un savoir" (p. I84).La méthode pédagogique de Bovelles repose donc sur « l'invention de médiations sensibles - texte, figures, images - qui servent la pensée et la rendent accessible à autrui » (p. I94). Le chapitre X s'attache au plan du traité pour en dégager les questions philosophiques en jeu et les modèles implicites ou explicites auxquels Bovelles se réfère. Un élément particulièrement intéressant est la supériorité de l'ouïe sur la vue que défend avec vigueur le philosophe, à rebours de la pensée ficinienne qui exalte la lumière et l'excellence de la vue (pp. 2I8-2I9). Il est également intéressant de noter que “ le De sensu développe sa propre réflexion avec beaucoup plus d'indépendance que nombre de ses contemporains à l'égard de la théologie et du récit biblique des origines de l'homme » (p. 240).

La quatrième partie propose une analyse de la figuration, médiation sensible par excellence. Bovelles élabore en effet " une pensée par images » (p. I9). Cette dernière partie, particulièrement originale et instructive, interprète les moyens graphiques mis en œuvre au service de la démonstration philosophique et met en lumière « une pensée philosophique où l'image prime bien souvent sur le concept, ou permet du moins d'expliciter le contenu des termes conceptuels » (p. 257). «La figure », comme le souligne Bovelles lui-même, "offre une aide non négligeable à la saisie d'un savoir plus caché » (p. 28I). A.-H. Klinger-Dollé établit un parallèle éclairant avec les recueils emblématiques alors en plein essor (p. 29I) et souligne l'inscription de Bovelles dans la tradition des arts de mémoire (p. 3og). Chez Bovelles, comme dans l'emblème, texte et figure, loin de se redoubler, se complètent (p. 3o4). Les figures revêtent donc de multiples fonctions : “ aide pour la mémoire, support de l'évidence intellectuelle, moyen didactique savoureux » (p.327).
Ces analyses fines et fournies, complétées de quatre annexes, sont donc suivies du texte latin du De sensu, traduit avec élégance et précision, et dont les notions essentielles ont été fort bien mises en lumière par la première moitié du travail. L'ouvrage comporte en outre une riche bibliographie et de précieux index (des personnes, des noms de lieux et institutions et des matières et notions) qui permettent une navigation aisée dans le commentaire.

Ce livre constitue donc un ouvrage de référence et outil de travail précieux, aussi bien pour les philosophes que pour les spécialistes de littérature, française ou néo-latine. Il ajoute en outre une pierre à l'édifice de l'histoire du livre illustré à la Renaissance.

Laure Hermand-Schebat Université Jean Moulin-Lyon 3 laure.hermand@univ-lyon3.fr

\section{Egidia Occhipinti, The Hellenica Oxyrhynchia and Historiography: New Research Perspectives, Leyde et Boston, Brill, 20ı6, 306 p., I29€ / ISBN 9789004325715.}

L'ouvrage présente une étude historiographique des Hellenica Oxyrhynchia qui s'efforce de définir la relation entre ce texte écrit comme une continuation de Thucydide et traçant l'histoire de la Grèce à la fin du v ve s. et au début du Iv ${ }^{\mathrm{e}} \mathrm{s}$. av. n. è., les autres œuvres à caractère historiographique de l'époque classique, et, plus à la marge, la rhétorique et le corpus hippocratique. L'étude historiographique passe également par une confrontation entre les $H O$ et l'œuvre de Diodore de Sicile.

Le chapitre introductif présente le texte, ses éditions et ses sources, trois papyri des deux premiers s. ap. n. è., et fait le point sur les questions qu'il soulève: sa date de composition (E. Occhipinti proposera 
au cours de son étude la fin des années 350 ou peu après, 346 au plus tard); son auteur; sa méthode et ses buts; le lien avec les Helléniques de Xénophon, ainsi qu'avec Théopompe et Éphore. Les outils de l'intertextualité et de la narratologie appliqués à l'historiographie permettront ici de reprendre ces débats à nouveaux frais et de considérer les $H O$ en tant que production littéraire, inspirée notamment de l'épopée.

Le livre est ensuite divisé en deux parties. Dans la première, l'auteure se livre à une analyse serrée des $H O$ en relation avec les sources qui rapportent les mêmes faits. Le chap. 2 explore les caractéristiques de la narration proposée dans l'œuvre: il s'agit d'une narration continue qui traite séparément de trois fronts contemporains, mêlant l'annalistique et le synchronique, et qui en cela associe des caractéristiques à la fois de Thucydide et d'Hérodote et est comparable à la manière de Théopompe en particulier. Dans le chap. 3, EO examine les raisons pour lesquelles, selon le narrateur des $H O$, plusieurs cités grecques du continent furent amenées à s'opposer à Sparte lors de la guerre de Corinthe, et les motivations spartiates pour mener une entreprise militaire en Asie mineure. Le point de comparaison privilégié est ici les Helléniques. EO en déduit que le matériau utilisé dans les $H O$ était principalement Xénophon, auquel le narrateur répondit cependant en ajoutant des informations perses. Les deux textes partagent notamment la même topique autour de Cyrus, mais s'écartent sur d'autres points, comme les raisons pour lesquelles l'expédition d'Agésilaos s'interrompit. Le chap. 4 propose une nouvelle lecture de la relation entre les $H O$, les Hell. et l'œuvre de Diodore de Sicile : il s'agit notamment de voir comment ce dernier concilie l'histoire du rve. s., le vocabulaire grec et les modes et idéologie de l'historiographie romaine, en examinant notamment les liens entre ses livres XIV et XV et les $H O$. Contre l'idée commune que Diodore aurait connu les $H O$ et les Hell. à travers Éphore, EO défend une lecture directe en s'appuyant sur des exemples précis. Pour elle, Diodore ne se limite cependant pas à répéter les $H O$ mais les condense, voire les simplifie, dans un sens moralisant et didactique qui ignore parfois la complexité réelle des événements et situations politiques décrits.

La seconde partie du livre rassemble cinq chapitres thématiques. Le chap. 5 étudie le traitement par les $H O$ du thème de la polypragmosynè athénienne : le terme désigne un activisme exagéré qui permet de comprendre la politique étrangère d'Athènes et ses motivations profondes, en particulier dans le déclenchement de la guerre de Corinthe. Alors que Thucydide qualifiait par ce terme Athènes comme ensemble homogène, le narrateur des $H O$ l'applique lui plus précisément aux démocrates, dans une peinture qui n'est pas toujours cohérente: c'est que les $H O$ appliquent à l'époque décrite les caractéristiques de la seconde ligue athénienne, plus tardive. Au chap. 6, EO étudie la perception que montrent les $\mathrm{HO}$ et les Hell. de l'hégémonie en Grèce: si Thucydide insistait sur la prépondérance de l'hégémonie maritime, les historiographes ici envisagés s'intéressent davantage à l'hégémonie continentale, ce qui explique notamment les développements sur la constitution béotienne dans les $H O$ ou sur certains événements se déroulant sur le continent. Le chap. 7 poursuit l'étude du thème de l'hégémonie en mettant en regard les $H O$, Xénophon et Diodore. L'auteure montre comment les trois textes reprennent, chacun à sa façon, des paradigmes construits depuis le $\mathrm{v}^{\mathrm{e}} \mathrm{s}$. et qui, s'ils ne sont plus adaptés à la situation postérieure, gardent cependant une efficacité rhétorique, comme en témoigne d'ailleurs leur confrontation avec la production oratoire du $\mathrm{IV}^{\mathrm{e}} \mathrm{s}$. Une opposition duelle figée et simplifiée se cristallise en effet, en particulier chez Diodore, pour 
décrire les affaires extérieures (Athènes us Sparte, mer us continent) avec son correspondant pour les dissensions internes (polloi-dèmos vs oligoi). Au chap. 8, l'auteure étudie la manière dont les $H O$ reprennent le langage politique utilisé par Thucydide et en particulier sa théorie de la causalité, avec les thèmes liés : responsabilité individuelle et collective; causes manifestes, réelles, alléguées; thème de la stasis. Y est lié le “ moralisme » que l'auteure décèle dans les $H O$ et qu'elle aborde dans son neuvième et dernier chapitre: d'après son analyse, le moralisme du texte a pour première fonction d'améliorer notre compréhension des événements, avant même d'enseigner une conduite éthique et de transmettre en cela un héritage pour les futures générations de dirigeants (ce que font plutôt Xénophon, Théopompe et Éphore), ou de dégager des principes psychologiques généraux.

L'ouvrage comporte quatre appendices (une discussion sur le papyrus de Théramène; un prolongement au chap. 7 sur le lien entre historiens et orateurs au $\mathrm{IV}^{\mathrm{e}} \mathrm{s}$.; un prolongement au chap. 4 sur les rapports entre Diodore et l'historiographie romaine; des traductions d'extraits), une bibliographie, un index des noms et un index thématique.

Anne de Cremoux

Université de Lille anne.de-cremoux@univ-lille.fr

Laurent Olivier (dir.), La mémoire et le temps. L'ouvre transdisciplinaire d'Henri Hubert (I872-1927), Paris, Demopolis, 20I7, 347 р., 3г,5о є/ ISBN 978235457 I2I4.

Sa vie durant, Henri Hubert (I872-I927) se trouva dans une position d'entre-deux : historien aspiré par les sciences sociales, archéologue sans fouilles, voyageur intermittent, sociologue méfiant à l'égard des idées trop générales. À l'occasion du $9 \mathrm{o}^{\mathrm{e}}$ anniversaire de sa mort et du $\mathrm{I} 5 \mathrm{o}^{\mathrm{e}}$ anniversaire du Musée d'Archéologie nationale (MAN) de Saint-Germain-enLaye, les contributeurs de ce volume rendent hommage à Hubert, qui incarna ce qu'au début du $\mathrm{xx}^{\mathrm{e}}$ siècle l'archéologie française pouvait avoir de plus ambitieux : une archéologie ne se voulant plus la simple féale de l'histoire, mais ouverte aux autres sciences de la société, spécialement la sociologie. L'activité professionnelle d'Hubert se déploya principalement au MAN, où il travailla dans l'ombre de Salomon Reinach, le conservateur en chef. Son œuvre ne prit jamais réellement forme en raison de ses difficultés de santé et d'une mort prématurée, mais aussi de ses fonctions administratives qui l'accaparèrent: il mit beaucoup de soin et d'énergie à acquérir quantité d'objets pour le Musée. Il souffrit aussi de certaines difficultés à mener jusqu'à leur terme les co-écritures entreprises avec Marcel Mauss, qui fut - malgré un tempérament très différent, plus flamboyant - son jumeau scientifique et son ami intime. Normalien, agrégé d'histoire, excellent helléniste, Hubert, nommé également directeur d'études à l'EPHE, fut tenté par l'histoire byzantine et les études orientales, mais ne termina jamais sa thèse sur la Déesse syrienne. Dans le présent ouvrage, ces jalons biographiques sont bien restitués par Ivan Strenski.

Comme Marcel Fournier le relate par la suite, Henri Hubert collabora activement à la jeune Année Sociologique, dirigée par l'oncle de Marcel Mauss, Émile Durkheim. De son vivant, il écrivit d'innombrables comptes rendus et quelques études marquantes de sociologie religieuse, dont l'“ Étude sommaire de la représentation du temps dans la religion et la magie » (I904), sur laquelle Thomas Hirsch revient dans ce volume, mais aussi - en collaboration avec Mauss - l'، Essai sur la nature et la fonction du sacrifice» (I899) et l'“ Esquisse d'une théorie générale de la magie » (IgO2). Quant 
à ses synthèses sur Les Celtes (1932) et Les Germains (I952), elles ont été éditées à titre posthume.

Hubert ne fut jamais un homme de terrain, mais il développa une conception originale de l'objet archéologique et de sa muséographie. Non sans hériter de directives antérieures, notamment celles de Gabriel de Mortillet, il mit sur pied à partir de I9ıo, dans la salle du château de Saint-Germain, une étonnante salle de comparaison conçue comme un “microcosme». Hubert comprit sans délai l'importance du comparatisme dans l'appréhension du matériel archéologique, ce que Laurent Olivier résume ainsi : « bien avant la révolution de la New Archaeology américaine, Hubert ouvrait l'archéologie à l'ethnographie et aurait pu faire sien le mot d'ordre qu'allait populariser Lewis Binford au début des années 1960: Archaeology is Anthropology or it is nothing " (p. 120), tandis que les linéaments de la pensée sociologique d'Hubert sont exposés ici par Serge Lewuillon.

L'ouvrage aide donc à mieux cerner la trajectoire d'un individu au profil presque effacé, mais qui comprit les grands enjeux de la discipline archéologique telle qu'elle se développait depuis le xIx $^{\mathrm{e}}$ siècle. Hubert saisit de la sorte les menaces portées par les interprétations racialistes de Vacher de Lapouge et du linguiste allemand Gustaf Kossinna (I858-I93i) prompt à parer les anciens Germains de toutes les qualités: première domestication du cheval, première métallurgie du bronze et même invention de l'alphabet! Pour Hubert, au contraire, il était dangereux de faire intervenir les caractéristiques biologiques des populations dans le champ de l'archéologie.

Ce volume permet en outre de retrouver l'atmosphère d'une époque de grande ébullition intellectuelle, à la veille de la Première Guerre mondiale. Les sciences humaines et sociales n'ont jamais été aussi ouvertes les unes aux autres qu'en ce temps.
Ce fut le moment où, pour sa collection “L'Évolution de l'Humanité », Henri Berr rassembla autour de lui plusieurs jeunes savants enclins à la transdisciplinarité, dont Henri Hubert. Mais la guerre décima les rangs de cette génération scientifique: « Notre groupe ressemble à ces petits bois d'une région dévastée où, pendant quelques années, quelques vieux arbres, criblés d'éclats, tentent encore de reverdir ", constatait tristement Marcel Mauss en I925 (p. 77). Après s'être mis au service du ministre de l'Armement Albert Thomas à partir de Igı5 (contribution de Marine Dhermy-Mairal), Hubert survécut au conflit mondial, puis poursuivit son activité au MAN, quoique de manière moins soutenue, et ce jusqu'à sa mort en I927. Une vie brève, donc, mais qui laissa son empreinte: les cours qu'il donna à l'École pratique, ou à l'École du Louvre, eurent une influence discrète. Il patronna les recherches sur l'art irlandais de Françoise Henry (Igo2I982) et dirigea les travaux d'un étudiant polonais Stephan Czarnowski (1879-1937), auteur d'un ouvrage singulier: Le culte des héros et ses conditions sociales. Saint Patrick, héros national de l'Irlande (I9I9). Un chapitre signé Damien Thiriet et Joanna Wawrzyniak s'intéresse à ce surprenant héritage polonais d'Hubert.

Laurent Olivier et ceux qui l'accompagnent ont donc contribué, par ce volume, à recomposer le parcours d'un savant qui voulait faire de l'archéologie une science sociale à part entière. Le travail d'édition est soigné et les coquilles sont rares (il est vrai que l'épouse d'Hubert est tantôt appelée Anna, tantôt Alma, tantôt Emma...). Le lecteur trouvera en fin d'ouvrage une biographie sommaire, puis une bibliographie complète (I894-I979) d'Henri Hubert, ainsi qu'un portfolio de huit figures. On pourra regretter que l'influence du protestantisme de sa mère ou les années de formation du savant n'aient pas été davantage explorées, mais l'ensemble de ce livre constitue 
néanmoins une belle entreprise d'histoire intellectuelle.

Sarah REY

Université polytechnique Hauts-de-France sarah.rey@uphf.fr

Gabriella Pirontr et Corinne Bonnet (dir.), Les dieux d'Homère. Polythéisme et poésie en Grèce ancienne, Kernos, Supplément 3I., Liège, Presses Universitaires de Liège, 20I7, 262 p., 25 euros /

ISBN 978-2-87562-I3o-6

Cet ouvrage collectif, dirigé par G. Pironti et C. Bonnet, est le fruit d'un atelier de recherche qui s'est tenu à Rome, entre l'Academia Belgica et l'École Française de Rome en septembre 20I5. Publiés dans un premier temps en italien chez Carocci Editore, ces actes sont désormais disponibles en français à l'attention des chercheurs en quête d'un renouvellement dans l'approche des poèmes homériques. L'ouvrage propose ainsi une relecture multiple de l'Iliade et de l'Odyssée à la lumière du polythéisme qui les habite.

L'objet de la réflexion, tel qu'il est posé en introduction par les directrices de l'ouvrage, est double : armé des outils issus de l'anthropologie des mondes anciens, il s'agit de prendre toute la mesure de l'importance des dieux d'Homère dans la compréhension des poèmes euxmêmes, mais également dans la manière d'appréhender le fonctionnement du polythéisme grec.

L'ouvrage se décline en trois grandes parties. La première, intitulée « Raconter les puissances divines », fait intervenir, dans un premier chapitre, une étude de M. Bettini portant sur les régimes de visibilité des dieux homériques. L'auteur montre que l'aspect des dieux varie selon le registre narratif dans lequel ils se trouvent : divin ou humain. Ce dernier est ainsi le théâtre d'une variété de procédés de mise en présence - ou de camouflage - des dieux dont la principale caractéristique serait d'être insaisissable, sans forme fixe initiale et "vraie », amenant ainsi à délaisser la notion de “métamorphose» au profit de celle de « morphose » ou de " diamorphose » (p. 26) lorsqu'il est question de l'apparence des puissances divines. Poursuivant dans le registre des perceptions du divin, A. Grand-Clément propose, dans le deuxième chapitre, une réflexion autour des rôles des couleurs et des sens dans les poèmes. L'étude prête une attention particulière aux modalités des contacts physiques entre hommes et dieux ainsi qu'à l'association de couleurs spécifiques à certaines divinités ce qui, suivant un raisonnement "théo-logique », permet de définir un peu plus leurs champs d'action. Pour clore cette première partie, G. Pironti consacre le troisième chapitre aux rôles charnières - et complémentaires - de Zeus et d'Héra dans la mécanique des récits homériques. L'étude s'arrête en particulier sur un épisode du chant VI de l'Iliade, la Dios apatē, qui voit Héra mobiliser tout un arsenal de puissances pour littéralement endormir la méfiance de Zeus et agir selon son propre dessein, tout en actionnant un rouage essentiel à la poursuite du plan de Zeus. Ainsi, tout en demeurant le “ réalisateur absolu » (p. 83) de sa boulē, Zeus doit compter avec les volontés des autres divinités, en particulier celle de sa sœur-épouse qui sans cesse agit et réagit, avec et contre lui.

La deuxième partie nous fait circuler “Entre l'Olympe et la terre », d'abord à travers l'analyse des scènes d'assemblée divine proposée par C. Bonnet dans le quatrième chapitre, qui propose d'y voir des laboratoires du polythéisme. L'assemblée des dieux est un espace hiérarchisé : les discussions et les conflits qui l'animent s'acheminent toujours vers l'accomplissement de la boulē suprême de Zeus, tout en s'accommodant des 
“dynamiques interpersonnelles»(p. 9o). Par ailleurs, ces rassemblements, qui ne sont pas une spécificité du monde grec, ont un impact sur la vie des hommes, ce que les représentations figurées traduisent par une organisation verticale en registres qui montrent les dieux calmement observer l'agitation humaine. Le chapitre 5 s'intéresse ensuite aux puissances de médiation par le biais d'une étude de C. Pisano qui sonde le fonctionnement d'Iris et d'Hermès dans les poèmes, mettant en évidence à la fois des prérogatives propres à chacun - étroitement liées aux contextes narratifs dans lesquels ils interviennent - et la flexibilité du langage polythéiste d'Homère. C. Pisano suggère ainsi de s'intéresser moins aux modes d'action semblant prédisposer une divinité plutôt qu'une autre à agir dans un contexte donné, qu'à la façon dont les divinités choisies comme médiatrices "réagissent " à une situation pour mieux en saisir le fonctionnement. Le chapitre 6, proposé par V. Pirenne-Delforge, clôt cette partie en abordant un mode de communication particulier entre mortels et immortels : le rituel. La façon dont il est reçu par les dieux et les réponses que ceux-ci y apportent ont un impact sur la trame narrative et si le sacrifice reste le canal privilégié de cette communication, les poèmes en proposent de nombreuses variations dont l'issue demeure toujours incertaine, à la discrétion des dieux et, finalement, de Zeus. Cette incertitude montre qu'il n'existe pas, chez Homère, de procédure rituelle qui permette de se rendre automatiquement propice une divinité.

La troisième et dernière partie de l'ouvrage, intitulée “ De la guerre au salut » rassemble trois chapitres qui traitent de ces deux concepts dans une perspective qui engage les dieux comme les humains. P. Payen consacre ainsi le chapitre 7 au problème de la guerre - comprise comme un phénomène social - tel qu'il se présente aux dieux et aux mortels, en particulier dans l'Iliade. Le champ de bataille troyen constitue alors un espace propice à la manifestation de la présence divine. Les dieux - dans l'ensemble favorables à la guerre, moteur de l'intrigue - s'y affrontent entre eux et affrontent également des héros. Ces derniers tentent parfois de s'extraire des conflits, mais ce comportement n'emporte pas la faveur de Zeus dont le plan reste invarié. Ainsi, la guerre est une “nécessité interne à l'intrigue» (p. ı62), mais elle est toutefois remise en question à plusieurs reprises. Le chapitre 8 s'intéresse quant à lui aux causes de la guerre de Troie que D. Bouvier propose de chercher dans la puissance d'Aphrodite, tout en se livrant à une analyse historiographique du postulat d'A. Momigliano qui faisait de la guerre un fait de nature inhérent la société grecque. D. Bouvier démontre ainsi que le polythéisme grec a pensé la guerre et le conflit en les intégrant en tant qu'entités divines à part entière - par antonomase, ce qui induit une ambiguïté sémiologique mais aussi en les incorporant aux sphères d'influence de différentes divinités. L'étude de M. Herrero de Jáuregi, proposée au chapitre 9, vient alors conclure la troisième partie, et l'ouvrage dans son ensemble, en questionnant la " puissance salvatrice» des dieux d'Homère par le biais d'une analyse tout aussi originale qu'inédite du vers 23i du chant III de l'Odyssée, appréhendé comme une gnōmè formulée par Athéna et dont les termes permettent un examen $\mathrm{du}$ fonctionnement de l'assistance divine auprès des mortels des poèmes homériques.

L'ouvrage remplit pleinement son objectif de proposer une relecture des poèmes homériques “à l'aune du polythéisme » (p. 8). À la lumière des différentes études qui forment les chapitres, le lecteur peut envisager ces œuvres d'une manière qui remet "en messoisi » ce que les épopées d'Homère peuvent nous apprendre du fonctionnement du polythéisme grec.

Sandya Sistac

Université Toulouse - Jean Jaurès sandya.sistac@univ-tlse2.fr 
Rabun TAYLOR, Katherine W. Rinne et S. Kostof, Rome. An Urban History from Antiquity to the Present, Cambridge, Cambridge University Press, 20I6, 432 p., $£ 85.00$ / ISBN 978rio76oi499.

L'ouvrage propose une synthèse ambitieuse sur l'évolution de l'Vrbs, de l'âge du fer à l'époque contemporaine. Trois mille ans sont passés au crible, afin de dégager les grands traits de l'urbanisme romain, ses permanences et ses mutations. Le projet éditorial est en fait intrinsèquement lié à l'œuvre de S. Kostof (I936-I99I), spécialiste d'histoire urbaine romaine. Ses travaux inédits et légèrement remaniés constituent ainsi la trame principale de l'ouvrage (chapitres I5-23 et 25).

Une très brève introduction (p. I-3) et trente-cinq chapitres structurent la réflexion. Même si l'étude est diachronique, la moitié des chapitres concerne néanmoins l'Antiquité. L'introduction met en avant l'originalité du projet ayant pour but de livrer une "urban biography» dans une perspective globale. Toutefois il est regrettable que l'introduction ne dresse pas un bilan historiographique et se contente d'un paragraphe, sans référence précise au moindre ouvrage. En fait c'est un parti pris qui se retrouve dans l'ensemble du livre, car le but est d'offrir un manuel facile d'accès, notamment pour les étudiants et leurs enseignants. Il n'y a d'ailleurs pas de notes de bas de page, les références sont très réduites et il n'est guère fait état de controverses archéologiques ou historiographiques.

Les premiers chapitres très brefs de K. Rinne concernent l'Antiquité et alternent entre une approche tantôt chronologique tantôt thématique, en brouillant quelque peu la compréhension générale. Les chapitres thématiques intègrent des exemples républicains et impériaux. D'abord le chapitre " $A$ bend in the river " s'intéresse au site et à la situation de l'Vrbs (p. 4-9). Après l'approche géographique, l'auteur s'inté- resse rapidement aux premiers développements urbains jusqu'au $\mathrm{I}^{\mathrm{er}} \mathrm{s}$. av. J.-C. (« $A$ storybook beginning » et “Ideological crossfire », p. Iо-3I). Les transformations tardorépublicaines et augustéennes font l'objet des chapitres suivants ( Big men on the Campus » et “Res publica restituta » p. 32-5I). Les chapitres sont ensuite plus thématiques, notamment sur les funérailles, les festivités, les processions pour «Memorials in motion: spectacle in the city" (p. 52-59) et l'architecture (“The concrete style » p. 60-7I). Les chapitres suivants (“Remaking Rome’s public core 1-2 ", "Crisis and Continuity ") renouent avec la chronologie pour s'intéresser à l'activité édilitaire des Flaviens aux Sévères, avec un élargissement vers le reste du $\mathrm{II}^{\mathrm{e}} \mathrm{s}$. (p. 72-IO2). "Rus in urbe: $a$ garden city" s'intéresse à la ceinture verte de Rome et à des constructions, comme les portiques (p. I02-II3). Les chapitres « $A d m i$ nistration, infrastructure, and disposal of the dead» (p. II4-I2I) et “Mapping, zoning, and sequestration $)($ p. I22-13I) abordent la rationalisation de la gestion d'une ville millionnaire à l'époque impériale. Le quatorzième chapitre ( Tetrarchic and constantinian Rome », p. I32-I/4) traite aussi de la réception de cette période charnière à travers la maquette de la Rome constantinienne réalisée par I. Gismondi dans les années ig3o.

Le travail posthume de S. Kostof débute par deux chapitres sur la christianisation de l'Vrbs (“Trophies and tituli: christian infrastructure before Constantine» et "Walls make christians: from fourth to fifth century ", p. I42-159). Les chapitres suivants oscillent entre l'époque tardive et le Moyen Âge, en s'intéressant au processus de “médiévalisation» de Rome (“A tale of two Romes ", p. I6o-I69) et à l'évolution chronologique ("The Rome of Goths and Byzantines " et "Christian foundations " p. I70-187), tout en insistant sur les mutations du paysage urbain antique à l'époque médiévale («From domus Laterani to romanum palatium ", "The leonine city: St. Peter's and the Borgo", "Via papalis, 
the christian decumanus» et "The urban theaters of imperium and $S P Q R$ » $\mathrm{p}$. I88-22I). Puis l'intérêt se porte sur la vie quotidienne à travers l'habitat et la réutilisation des édifices antiques, voire leur fortification et leur occupation par des grandes familles ("Housing daily life" et "Chaos in the fortified city ", p. 222-240).

Dans le vingt-sixième chapitre, R. Taylor étudie le caractère essentiel du Tibre, de la fin du Moyen Âge à l'époque contemporaine (“The Tiber river», p. 24I-25o), puis on retrouve des chapitres chronologiques ( Humanist Rome, absolutist Rome (I42OI527) " et "Planning counter reformation Rome ", p. 25I-270). La mise en scène des festivités et des processions dans l'espace urbain est étudiée («Processions and populations » p. 27I-280), avant de voir les évolutions du paysage à travers l'étude des monuments emblématiques et des courants artistiques ( Magnificent palaces and rhetorical churches", "Neoclassical Rome » et “Picturing Rome », p. 28I-3I2). Le propos redevient chronologique dans les chapitres "Revolution and Risorgimento" et “Italian nationalism and romanità 》 (p. 3i3-335). Enfin le dernier chapitre “ $A$ city turned inside out » (p.336-347) a pour cadre une vaste période allant de l'époque fasciste à 2016.

Pour conclure, cette synthèse constitue une première approche plaisante et richement illustrée (228 illustrations en noir et blanc). Les nombreuses cartes et plans originaux ou repris d'autres ouvrages sont particulièrement utiles. Toutefois on peut regretter l'absence de grandes cartes à différentes périodes. Tout est mis en œuvre pour simplifier le propos. Par commodité chaque chapitre est assorti par exemple d'une bibliographie sélective. Cependant la simplification trouve parfois ses limites. Ainsi les sources littéraires sont certes données en traduction (conformément à l'optique d'un manuel), mais les références précises sont absentes. Il y a juste le nom de l'auteur (p. 53), voire de l'ouvrage (p. II3), ce qui complique la tâche du lecteur.

Cyrielle Landrea

Université Bretagne Sud cyrielle.landrea@univ-ubs.fr

Wyger Velema et Arthur Weststeijn (éd.), Ancient Models in the EarlyModern Republican Imagination, Leyde et Boston, Brill, 20I8, xi + 340 p., I27 €/ ISBN 9789004351387.

Questo volume si propone di investigare «il ruolo concreto degli specifici modelli repubblicani antichi nel pensiero politico delle repubbliche di prima età moderna» (p. 7). Si tratta di analizzare il modo in cui gli scrittori che allora si ispiravano a un ideale politico repubblicano - soprattutto all'interno dei paesi che aderivano ad una tale forma di governo - ricorrevano alle teorie politiche di epoche precedenti e agli esempi dell'antichità per “chiarire» e “legittimare» la forma di governo da loro difesa.

La maggior parte dei lavori che compongono il volume è dedicata all'esperienza olandese tra Sei e Settecento (così i saggi di A. Weststeijn, J. Nieuwstraten, W. Krul, W. Velema e R. Koekkoek). Ma è anche preso in considerazione il dibattito repubblicano nella penisola italiana (nei saggi di J. Bros e B. Straumann, nonché in quello di A. Weststeijn), in Svizzera (Th. Maissen), nella Francia dell'illuminismo (sempre W. Krul), negli Stati Uniti settecenteschi (E. Shalev), nella confederazione polacco-lituana (T. Gromelski), nonché (per quanto riguarda, in questo caso, la trasformazione degli appelli ad un modello ateniese) in Inghilterra tra Sei e Settecento (Ch. Zabel).

L'interesse degli autori oscilla tra due campi di indagine: da una parte, quello delle realtà repubblicane moderne, con i loro pensatori di fede repubblicana e la 
loro riflessione rivolta alla concreta azione politica; dall'altro, quello dei modelli antichi, greci, romani e anche ebrei, richiamati all'interno delle discussioni sulle esperienze politiche moderne (al modello greco è dedicato in modo più esclusivo il saggio di W. Stenhouse; a quello ebraico, il saggio di G. Bartolucci). Avendo come punto di partenza gli studi contemporanei sul repubblicanesimo, e più specificamente i lavori ormai classici della cosiddetta «scuola di Cambridge», il volume cerca di esplorare alcuni temi rimasti, da questa prospettiva, in una posizione marginale. Ciò giustifica la particolare attenzione che vi è dedicata al mondo olandese e, per quanto riguarda gli antichi, ai modelli greco ed ebraico. Di conseguenza, un minore spazio è riservato alla riflessione politica inglese e agli esempi tratti dal mondo romano, temi più spesso affrontati dagli studiosi del pensiero repubblicano.

Il volume presenta soprattutto dei contributi sui pensatori che vissero nei paesi di esperienza repubblicana; e cioè, paesi nella cui realtà politico-istituzionale è stato possibile riscontrare alcune delle caratteristiche proprie delle repubbliche antiche. Sono analizzate soprattutto delle opere di riflessione politica-cthe republican imagination»-, piuttosto che delle concrete esperienze politico-istituzionali. Non si considera, però, almeno in linea di massima, il pensiero di matrice repubblicana quando sviluppato al di fuori di una tale cornice geografica, o altrimenti - all'interno delle realtà «repubblicane» -, le forme di antirepubblicanesimo. Il volume ha come oggetto principale di analisi pensatori che aderirono alla causa repubblicana nei loro paesi di origine o di adozione. Per quanto riguarda il mondo antico, piuttosto della vera e propria “repubblica» romana, sono richiamate le analoghe realtà politiche che servirono da modello alla riflessione moderna. Il passaggio tra antico e moderno è il tema centrale di queste indagini.
È nell'ambito dei richiami ai modelli antichi alternativi a quello della Roma repubblicana che gli studiosi della fortuna dell'antico potranno trovare un più grande interesse per questo volume, che include contributi originali su argomenti poco frequentati. Come affermano i curatori nell'introduzione («Classical Republicanism and Ancient Republican Models»), i saggi raccolti intendono riconsiderare il dibattito sul repubblicanesimo classico «in una prospettiva transnazionale», rivelando non solo il modo in cui i modelli antichi erano percepiti come moralmente validi, in termini di virtù e di libertà, ma come fonti di “importanti lezioni costituzionali». Si assume così che in questa eredità costituzionale - e non solo sul piano della «immaginazione» repubblicana - si trovi un elemento rilevante per la costruzione del mondo politico di età moderna. In direzione contraria, sono ricordate le osservazioni critiche del pubblicista olandese del Settecento, Elie Luzac, nell'ampio commentario allo Spirito delle Leggi di Montesquieu: le realtà politiche moderne denominate «repubblicane» e le repubbliche classiche richiamate come esempio "non hanno nulla in comune, tranne il nome». Una tesi come questa, che non di rado (anche se in forme più sottili) è riproposta nei lavori più recenti, rischia di oscurare un elemento centrale nello studio della eredità politica degli antichi, e cioè, la natura stessa di questa appropriazione lessicale, nella sua veste filologica e nella storia della trasmissione dei testi - una vera eredità, tutt'altro che casuale e al di sopra dei modelli politici e letterari, che resta ancora da approfondire adeguatamente in molti dei suoi aspetti. Il vigore del repubblicanesimo moderno dipende non solo dal gioco intellettuale consistente nel ricordo dei modelli di epoche passate (e nella presa di distanza da questi modelli), ma anche dal modo in cui il ricorso al lessico antico, di matrice greca e latina, ha permesso di dare vita alle nuove realtà costituzionali, anche 
quando non si riscontra nelle realtà antiche un modello per il presente.

Paulo Butti de Lima

Université de Bari, Italie paulo.buttidelima@uniba.it

Philip WaLsh (éd.), Brill's Companion to the Reception of Aristophanes, Leyde et Boston, Brill, 20I6, 433 p., I55 €/ ISBN 9789004270688.

La réception d'Aristophane a suscité plusieurs travaux ces dix dernières années, dans le sillage des études sur la réception des poètes tragiques. Paru deux ans après la somme de plus de mille pages réunies par S. Douglas Olson, le volume de 433 pages édité par Walsh pourrait faire pâle figure. Plusieurs chapitres méritent cependant largement le détour. C'est le cas par exemple du premier, dans lequel Niall Slater propose un panorama utile de la réception antique d'Aristophane, c'est à dire du devenir à la fois du texte et des représentations. Charles Platter parcourt ensuite les différentes approches interprétatives dont Aristophane a fait l'objet au $\mathrm{xx}^{\mathrm{e}} \mathrm{s}$. (féministe, politique, anthropologique avec Bakhtine, intertextuelle) et termine avec la prise en compte de la performance et des études de réception. Cette conception au sens large du champ de la réception, qui englobe celui des interprétations savantes, est tout à fait bienvenue et montre bien que les études de réception ne sont pas à côté des études classiques mais essentielles à toute étude sur un auteur donné : l'état de l'art fait partie de la réception, qu'il modèle à son tour. James Robson, "Aristophanes, Gender and Sexuality ", porte sur la réception "on the page, on the stage " des contenus sexuels chez Aristophane et plus précisément de Lysistrata dans le monde anglophone. Stavroula Kiritsi s'intéresse à la place d'Aristophane dans l'enseignement et les mises en scène pour enfants en Grèce; c'est un matériau peu exploré qu'elle présente là, en repartant du $\mathrm{XII}^{\mathrm{e}} \mathrm{s}$. byzantin, et qui permet de dresser bien des parallèles avec ce qui s'est fait dans le reste du monde. Le très beau chapitre qui suit, dû à Josh Given et Ralph Rosen, élargit encore, avec bonheur, le champ de la réception en s'intéressant à la place d'Aristophane dans l'enseignement des undergraduates aux États-Unis, dans le cadre de cours ayant pour objectif le développement des compétences en communication écrite et orale et de la pensée critique. Il présente deux expériences pédagogiques, celle d'un cours transversal sur le scandale et les arts dans les sociétés ancienne et moderne et celle d'une mise en scène de Lysistrata. Les deux posent la question de savoir ce que l'on souhaite qu'un étudiant non helléniste retienne d'Aristophane - qu'il résume pour sa part ainsi : " a desire to understand a distant past in terms that make sense to ourselves » (p.Io8) - et le meilleur moyen d'y parvenir. Matthew Kinservik centre son propos sur Fielding et Foote, qui tous deux furent qualifiés de “modern Aristophanes» dans l'Angleterre du XviII ${ }^{\mathrm{e}} \mathrm{s}$. Il propose une analyse fouillée des utilisations de la comparaison avec le poète comique et montre qu'elle est rarement positive. Mark Payne s'intéresse au rôle des animaux et plus généralement de l'animalité dans la comédie ancienne à la lumière des recherches récentes en études animales. Donna Zuckerberg analyse la construction de la persona du poète comique en dressant un parallèle avec des figures contemporaines de la culture populaire américaine comme Stephen Colbert ou Bill Cosby.

La seconde partie, "Outreach: Adaptations, Translations, Scholarship, and Performances ", s'ouvre sur deux chapitres consacrés à la réception d'Aristophane en France. Cécile Douduyt montre de manière très convaincante comment les deux tentatives françaises de réécrire Aristophane au xvI ${ }^{\mathrm{e}}$ puis XvII ${ }^{\mathrm{e}} \mathrm{s} .$, La Néphélococcugie de Pierre Le Loyer et Les Plaideurs 
de Racine, ne relèvent ni de la traduction ni de l'adaptation mais d'un mélange des deux, car l'on retrouve dans les deux cas de longs passages traduits mais aussi un profond remaniement notamment de l'intrigue. Rosie Wyles révèle comment Anne Dacier, en changeant le genre des deux Discours dans sa traduction des Nuées non seulement gomme le contenu homosexuel alors problématique de l'agôn, pour réhabiliter le poète comique et le rendre acceptable, mais aussi influe sur la réception notamment anglaise du poète et de cette comédie. Philip Walsh présente différentes traductions d'Aristophane en anglais au $\mathrm{XIX}^{\mathrm{e}}$ s., qui se caractérisent par une attention commune pour la métrique du poète comique et le souci de la rendre en anglais. Il poursuit avec la " traduction en images » de Lysistrata que constituent les illustrations d'Aubrey Beardsley; à la différence des traductions textuelles, ces illustrations n'expurgent pas la comédie et annoncent en cela la fascination qu'elle a suscitée au $\mathrm{xx}^{\mathrm{e}} \mathrm{s}$. Gonda Van Steen étudie une réécriture réflexive d'Aristophane due au poète grec Nikolaras, qui invente alors un genre proche de la revue et appelé à un bel avenir en Grèce. Le Cambridge Greek Play est évoqué par C.W. Marshall à travers le prisme d'un personnage, J.T. Sheppard, et d'une comédie, les Oiseaux, dans laquelle il joua, encore étudiant, le rôle de Peisthetairos en Igo3 avant de reprendre la pièce en ig24. Il montre de manière tout à fait convaincante l'entrelacement de l'évolution des études classiques à Cambridge et le rôle grandissant de l'outreach, dont le Cambridge Greek Play fut très tôt un élément essentiel. Mike Lippman analyse la réception d'Aristophane par le grand vulgarisateur que fut Gilbert Murray, davantage connu pour ses travaux sur Euripide : il dresse du même coup un panorama des différentes lectures savantes du poète comique dans la première moitié du xx $x^{\mathrm{e}}$. Gregory Baker expose le contexte nationaliste de réflexion sur la langue qui a vu naître les traductions d'Aristophane en Écosse, et l'importance politique de ces traductions. Le dernier chapitre est consacré à l'analyse de quarante affiches de mises en scène de Lysistrata; Alexandre Mitchell décèle deux grands courants, l'un “ traditionnel », donnant à voir des femmes se refusant aux hommes et les manipulant, et l'autre, qu'il qualifie de féministe, où l'on trouve de nombreuses allusions à l'iconographie pacifiste.

On le voit, les pistes sont nombreuses et riches. On pourra regretter que le volume n'accorde qu'une place très réduite au devenir d'Aristophane à Byzance, comme s'il s'agissait d'une parenthèse sans importance, limitée à la pure reproduction du texte, avant que l'Occident ne vienne lui redonner du sens. De la même manière, la réception du poète comique dans l'Europe de la Première modernité, essentielle, est en bonne partie passée sous silence : sans les contributions sur la France, ce qui se passe après la redécouverte du poète grec en Occident et jusqu'au $\mathbf{x v}^{2}{ }^{\mathrm{e}} \mathrm{s}$. est largement escamoté. L'apport fondamental de l'Italie, l'abondance des traductions latines, les expériences de mises en scène n'existent pas, alors qu'elles furent le terreau de l'explosion que connaît la réception du poète comique au $\mathrm{xvIII}^{\mathrm{e}} \mathrm{s}$. Plus généralement, même après cette date, l'apport de l'Italie, de l'Allemagne, de l'Espagne, du Portugal est absent. Cette réserve mise à part, on reconnaîtra à l'ouvrage, et notamment à l'introduction, une réflexion approfondie sur le concept même de réception. C'est peut-être en cela que ce volume est le plus intéressant, et se distingue de celui de Douglas Olson : par la manière réflexive dont il définit tout en l'élargissant le champ des études de réception.

Malika Bastin-Haмmou Université Grenoble-Alpes malika.bastin@univ-grenoble-alpes.fr 
Richard WARren, Art Nouveau and the Classical Tradition, Londres et Oxford, Bloomsbury, 2018, 232 p., £7o / ISBN 978I47429855I.

Telle la “ femme inconnue » de Verlaine, l'Antiquité classique, “ ni tout à fait la même, ni tout à fait une autre ", constitue un trésor - enrichi par l'archéologie, par exemple vers 1740-175o à Herculanum, Pompéi et Paestum - de formes, de motifs, de thèmes et de mythes, dans lequel chaque époque, mouvement politique ou courant artistique peut trouver inspiration, renouvellement, voire justification de son existence. Chaque époque possède “son » Antiquité, exploitable sans crainte d'épuisement du stock.

Un exemple évident, celui de la France artistique, littéraire et politique que tout "bon élève» du Secondaire connaissait autrefois et connaît peut-être encore aujourd'hui : Antiquité féconde et novatrice de la Renaissance et de la Pléiade, par le biais italien, avec tout de même du Bellay - un peu chagrin, mais si attachant - et ses chers " Loire gaulois », " petit Liré » et “ardoise fine» préférés aux prestigieux “Tibre latin », “ Mont Palatin » et « marbre dur »; Antiquité majestueuse et allant de soi du classicisme, avec ses références incontestables, des préfaces de Racine aux Caractères de La Bruyère, ou chez Boileau se prenant pour Juvénal, et encore dans les "sources » de La Fontaine, "sources» savantes, certes, mais aussi sources bien réelles, sous les platanes de la Grèce et du Midi français ; après la “Querelle des Anciens et des Modernes ", Antiquité plus discutée des Lumières, avec les Romains vertueux et républicains de Montesquieu et de Rousseau ; Antiquité-modèle de l'art néo-classique, jusqu'à Ingres, avec les dessins et tableaux révolutionnaires, puis napoléoniens, “à la romaine », de David et de son école, et l'architecture aussi, peutêtre moins ostensible qu'ailleurs en Europe - par exemple à Munich ou en Grèce, avec les architectes bavarois arrivés avec Othon $\mathrm{I}^{\text {er }}$ à partir de $\mathrm{I} 83 \mathrm{o}$-, mais toujours là jusqu'à présent, ne fût-ce que dans bien des bâtiments ministériels et parisiens; et encore l'Antiquité paradoxale de ce “classicisme des romantiques » signalé en I932 par Pierre Moreau ; puis celle, brûlante, voire "scandaleuse» de Baudelaire. Et cette liste irait jusqu'au milieu $\mathrm{xx}^{\mathrm{e}}$ siècle au moins, avec, entre autres, les deux amis Gide et Valéry.

L'étude érudite, méthodique et détaillée - parfois un peu ennuyeuse - de Richard Warren examine la forte présence de l'art de l'Antiquité classique, grecque surtout, de ses motifs, de ses thèmes et de ses mythes dans l'Art Nouveau, ce mouvement artistique qui s'est développé en Europe et aux États-Unis au tournant du $\mathrm{XIX}^{\mathrm{e}}$ au $\mathrm{Xx}^{\mathrm{e}}$ siècle, de I8go à I920, au sommet de cet “impérialisme, stade suprême du capitalisme » dont parla Lénine en IgI6, un an avant la contradictoire Révolution russe, celle de févier I9I7, puis celle d'octobre. En parlant d'un " stade suprême », Lénine était trop optimiste, car, en fait d'hégémonie, on a fait plus efficace depuis, du Texas et de la Californie à la mer de Chine et même à l'Europe pudiquement appelée « rhénane ».

L'Art Nouveau, vaste, sinon vraiment puissant courant artistico-décoratif, porte des noms différents selon les lieux : Art Nouveau de la France, à Paris et à Nancy, au Royaume-Uni, avec Beardsley, mort à vingtcinq ans, et, dans l'autre sens, Modern Style, terme encore utilisé par Aragon en ig65 dans sa préface (le « modern style » d'où je suis), à l'Art nouveau en Europe de R.-H. Guerrand, Jugendstil en Allemagne, Sezession ou Secession à Vienne et en Autriche-Hongrie, avec bien sûr Klimt, mais aussi Mucha, l'intéressant Tchèque en transit de Prague et Vienne à Paris, et les moins connus Polonais Malczewski et Wyspiański Cracovie et la Galicie dépendant de la double monarchie jusqu'en I9I8 - Liberty en Italie, entre autres à Palerme, vers le parc de la Favorite, Modernismo en Espagne, en 
Catalogne surtout avec Gaudi, et Tiffany aux États-Unis.

Après une introduction situant l'Art Nouveau dans son rapport à l'Antiquité classique, ou plutôt au "classicisme de l'Antiquité », Warren présente ses fiches de travail et ses réflexions bien ordonnées. Dans la stricte succession des chapitres, les motifs et les thèmes soigneusement étudiés sont ceux de la re-naissance (re-birth), de la muse, du héros, de la fleur, du désir, de la nation (l'auteur a codirigé en 20I6, avec T. Fögen, un collectif intitulé Graeco-Roman Antiquity and the Idea of Nationalism in the Igth Century, paru chez De Gruyter) - et enfin, très logiquement, de la mort. À chaque fois, ces têtes de chapitre sont associées à des noms d'artistes - ceux cités ci-dessus et quelques autres - et à des reproductions, malheureusement toutes en noir et blanc, chose surprenante pour un mouvement donnant explicitement dans le « décoratif ». L'Art nouveau diffère en effet des films d'Antonioni en ceci que le noir et blanc lui sied beaucoup moins que la couleur. Je ne cacherai pas que je préfère Antonioni à l'Art Nouveau, mais, me dira-t-on, où est le rapport? Peut-être, mais ce n'est qu'une hypothèse, du côté de la différence, précisément, entre l'art et la "décoration ».

$\mathrm{Au}$ sujet de la couleur, et sans aller jusqu'aux abondantes reproductions en couleurs d'un petit guide comme $L A B C$ daire du Symbolisme et de l'Art Nouveau (Flammarion, I997), le petit cahier central, en couleurs lui aussi, du livre de Guerrand cité plus haut (rééd. Perrin, 2009) paraîtra plus plaisant et efficace. Mais, dans les deux cas, le spectre thématique et formel était bien plus large que celui de la seule Antiquité ou de la seule esthétique antiquisante, dont on peut finir par se demander si elles justifiaient vraiment, à elles seules, un tel investissement de recherche.

Lucien Calvié Université Toulouse Jean-Jaurès claude.calvie@orange.fr
Jesse WeIner, Benjamin Eldon Stevens et Brett M. Rogers (éd.), Frankenstein and Its Classics. The Modern Prometheus from Antiquity to Science Fiction, Londres et Oxford, Bloomsbury, 20I8, 288 p., £65 (hardback) et $£ 21,99$ (paperback) / ISBN 9781350o54882 et 9781350054875.

En ı8ı8, Mary Shelley offrait un roman qui fit date dans la littérature horrifique et de science-fiction: Frankenstein ou le Prométhée moderne. À l'occasion $\mathrm{du}$ bicentenaire de sa publication, de nombreux ouvrages sont revenus sur le succès et la postérité de l'auteure, de Victor et de sa créature, dont celui pour lequel nous proposons ce compte-rendu de lecture. La figure de Mary Shelley et de ses personnages sont telles qu'elles permettent de tirer avantage d'un appareil critique que l'auteure a elle-même utilisé. Ce volume, du trio déjà à l'origine de quelques efforts sur la réception de l'Antiquité, regroupe douze essais d'universitaires, spécialistes de l'Antiquité pour la majorité. Ils sont également répartis en deux moments, “Promethean Heat » et «Hideous Progeny ».

Dans la première partie, les articles rappellent à la fois le contexte d'écriture de Mary Shelley ainsi que les références antiques et modernes qu'a réemployées consciemment l'auteure ainsi que celles de son entourage, à commencer par son mari Percy Shelley et le poète Lord Byron. Mais ce sont avant tout les auteurs classiques qui prévalent: Ovide, Eschyle et Hésiode sont convoqués pour comparer Victor au Prométhée ancien, ou au contraire le tourner en dérision. Il est tour à tour plasticator ou pyrophoros et peut avoir un lien avec l'alchimie chère à Paracelse ou avec la théorie de l'évolution de Darwin. À ce titre, les chapitres de Genevieve Liveley et Martin Priestman sont très éclairants. Quant à l'ambiance horrifico-romantique, elle est due à la fois à l'entourage immédiat de Mary Shelley, à l'histoire européenne ainsi qu'au phénomène naturel d'ampleur 
mondiale que fut l'éruption du volcan Tambora en Indonésie (voir les articles de Andrew McClellan, David A. Gapp et Suzanne L. Barnett). Le dialogue entre contemporanéité de l'écriture du roman et utilisation des auteurs anciens est très facilement compréhensible même pour les non-initiés à la période antique.

La deuxième partie réunit des articles qui, à la suite des premiers, interrogent la façon dont Frankenstein a été à son tour l'origine de nombreuses créations, comme pour mettre en abîme l'histoire du créateur qui est à l'origine d'une "progéniture hideuse et polymorphe ». En premier lieu, on relèvera l'excellent chapitre de Benjamin Eldon Steven rapprochant justement les constructions du roman de Shelley avec les textes d'Apulée. Les références scientifiques à la médecine, à la physique mais également à la psychologie sont aussi le ferment de Frankenstein comme le rappellent Carl A. Rubino et Nese Devenot dans leur chapitre respectif. Les références plus ou moins déguisées au roman de Shelley transparaissent largement dans la culture cinématographique comme le soulignent Jesse Weiner et Samuel Cooper ; c'est d'ailleurs là peut-être que s'est d'abord construite l'image populaire des personnages du roman, jusqu'à confondre le nom Frankenstein avec celui de sa créature. Victor Frankenstein est identifié comme l'avatar du réalisateur Bill Morrison dont l'œuvre qu'il a réalisée Spark of Being serait la créature au sens propre comme au sens figuré. Chez le réalisateur et scénariste Alex Garland, c'est le personnage de Nathan Bates dans Ex Machine qui joue à la fois le rôle de Prométhée et d'Épiméthée. Enfin, Brett Roger interroge à la fois le film de Ridley Scott Prométhée et le comic de Fraction et Ward $O d y$ - $C$ (sortie en France en mai 20I9), même si l'analyse du film est bien plus fournie que celle du comic du fait de leur destin populaire respectif.

Au final, il s'agit là d'un ouvrage d'une grande qualité, facile et agréable à lire. On regrettera cependant des redites historiographiques inhérentes mais nécessaires à ce type de projet.

$$
\begin{array}{r}
\text { Mathieu ScAPIN } \\
\text { Université Toulouse-Jean Jaurès } \\
\text { mathieu.scapin@gmail.com }
\end{array}
$$

Nigel G. Wilson, From Byzantium to Italy. Greek Studies in the Italian Renaissance, deuxième édition, Londres et Oxford, Bloomsbury, 20I7, 23i p., £25,99 / ISBN 978I474250474.

Faisant suite à la traduction française parue en 20ı5, De Byzance à l'Italie. L'enseignement du grec à la Renaissance (Paris, Les Belles Lettres, par H.-D. Saffrey), la deuxième édition, fort bienvenue, de l'ouvrage original en anglais comporte des additions, des remaniements et des mises à jour bibliographiques dans les notes de fin qui ne remettent pas en question l'architecture de la première édition (1992). C'est l'occasion de revenir sur une synthèse efficace et méritoire, s'adressant certes en premier lieu aux historiens de la philologie grecque et latine, mais conçue dans un esprit généreux parfaitement conforme à son objet et qui s'ouvre ainsi à l'histoire des idées et à l'histoire tout court, s'agissant d'événements qui croisent la Prise de Constantinople en i/553 et, en amont, le concile de Ferrare-Florence qui vit débarquer dans les États italiens une délégation pléthorique, conduite par l'empereur lui-même, de dignitaires byzantins, parmi lesquels se trouvaient les plus grands savants grecs. Le développement des " études grecques », au sens académique du mot, dans l'Occident médiéval tardif - d'abord dans plusieurs villes d'Italie et en Avignon, puis dans plusieurs pays d'Europe centrale et occidentale - est l'un des marqueurs de l'Humanisme, l'élément qui fait la différence par rapport au “Graecum est, non legitur » des 
universités médiévales, à la fois fierté du nouveau courant intellectuel et couronnement des efforts qui eurent lieu tout au long des siècles dits du Bas Moyen Âge pour la reconquête du savoir antique, vénéré dans sa majesté. L'immense transfert culturel que représente l'intégration dans l'Europe latine de la culture scolaire et supérieure byzantine présuppose l'apprentissage et la pleine maîtrise de la langue grecque ancienne et de ses dialectes, mais aussi du grec biblique et néotestamentaire, ecclésiastique et médiéval, au moins par une élite d'humanistes. S'ils ne parviendront au seuil de l'activité philologique proprement dite appliquée aux textes grecs qu'avec Valla et Politien, il ne faut pas oublier tout ce que la philologie latine, l'exégèse, l'histoire du livre doivent à ces érudits, maîtres, lecteurs, traducteurs, copistes, imprimeurs, collectionneurs; Wilson va jusqu'à montrer les effets de la lecture des textes nouvellement rendus disponibles dans des domaines plus surprenants comme lorsqu'il évoque, p. 64-65, Christophe Colomb lecteur de Strabon et des hypothèses que celui-ci relaie quant aux voies occidentales de navigation vers l'Inde.

Les modalités de ce grand effort collectif, initialement fourni par les Italiens du Quattrocento grâce à l'apport des Byzantins, sont ainsi au centre du volume de Wilson. Dans un ordre souple, mariant la nécessaire approche chronologique à la variété géographique comme prosopographique qu'offre l'Italie de cette période, quatorze chapitres présentent les temps forts et les protagonistes de cette rencontre civilisationnelle. Après un premier aperçu des prodromes au xIv ${ }^{\mathrm{e}}$ siècle (p. I-7), s'achevant sur l'année-charnière I397, quand les premiers cours stables de grec sont proposés à Florence, le chapitre 2 (p. 9-I4) met en scène leur professeur, le diplomate Manuel Chrysoloras, maître de la première génération d'hellénistes florentins et notamment de Leonardo Bruni, principal sujet du chapitre suivant (chapitre 3, p. I5-25), qui montre comment les principales cours italiennes ont rapidement été investies par ce nouveau savoir. Le chapitre 4 (p. 27-38), composite avec quatre sous-chapitres, fait le point sur la “Consolidation » de cette première réception, par exemple en insistant sur l'événement de ı/23, l'arrivée en Italie d'une entière cargaison de manuscrits grecs. Les chapitres 5 à 7 sont consacrés chacun à un personnage-clé de la période centrale du siècle: l'éducateur Vittorino de Feltre (p. 39-47), le grammairien Guarino (p. 49-54) et le lettré François Filelfe (p.55-6r). Comme on l'a dit, la venue du concile à Florence en 1439 , objet du chapitre 8 (p. 63-77), constitue un moment capital pour le mouvement hellénique en Occident, en particulier avec l'installation en Italie comme cardinal de Basile Bessarion, dont la fabuleuse bibliothèque fournira la base de la collection de Saint-Marc à Venise après sa mort en 1472 .

À partir des années I440, l'essor et l'enracinement des études grecques sont incontestables, avec Laurent Valla (chapitre 9, p. 79-87) et les programmes de traduction et bientôt d'impression qui fleurissent à Rome sous le pontificat de Nicolas $\mathrm{V}$ et après (chapitre Io, p. 89-98), mais aussi et surtout dans la Florence des Médicis (chapitre II, p. 99-II4) avec le savant bilingue Jean Argyropoulos, Ficino, traducteur $\mathrm{du}$ corpus platonicien, Chalcondylès et Lascaris, enfin avec le grand Politien, à qui est réservé le chapitre I2, p. II5-I28. Si le chapitre I3 (p. I29-I39) couvre des centres d'études grecques et humanistes mineurs, mais très vivants, comme Padoue, Bologne, Ferrare et Messine, par ailleurs mentionnés à propos des pérégrinations des maîtres déjà considérés, le long chapitre I4 (p. I/I-I76) se focalise sur le cas à part que représente Venise, en raison de ses imprimeurs exceptionnels et de sa vie culturelle imprégnée de culture grecque post-byzantine que résument les noms d'Alde Manuce et de Marc 
Mousouros ; l'année de leur mort, I5ı5, clôt symboliquement l'ouvrage (p. I75-I76). La narration - toujours menée avec brio, sans jamais tomber dans l'exposé acritique ou mystifiant $d u$ " miracle italien » - cède alors la place à une ample “Conclusion » (p. I77I83) où l'auteur disserte sur les mérites et les limites de la renaissance textuelle de la littérature grecque en Occident, signalant le fait que, si la crainte, largement répandue à l'époque, de rater la conservation d'œuvres littéraires à cause des conquêtes ottomanes a été largement dissipée grâce à l'action conjointe des Italiens et des Grecs, les pires dégâts pour la transmission culturelle avaient déjà eu lieu en ı204, lors de la conquête de Constantinople par les Latins de la Quatrième Croisade. Après les notes de fin, occupant les p. I87-220, le volume est complété par quatre index, des auteurs anciens, des médiévaux et renaissants, des manuscrits cités et un dernier, appelé “General » et incluant par exemple les noms de lieu et les thèmes, mais d'où sont absents les auteurs de la bibliographie moderne citée en note.

Luigi-Alberto SANCHI CNRS - Institut d'histoire du droit luigialberto.sanchi@gmail.com 
ANABASES

Traditions et Réceptions de l'Antiquité

Revue de l'équipe de recherche E.R.A.S.M.E.

Université Toulouse-Jean Jaurès (UT2J)

NoRMES RÉDACTIONNELLES

ANABASES publie des articles dans cinq langues : français, anglais, allemand, italien et espagnol.

Les articles ne dépasseront pas 35000 signes et seront conformes aux normes de la revue,

disponibles sur le site web : http://plh.univ-tlse2.fr

Les articles seront pourvus d'un résumé en français et en anglais, ainsi que de six à huit mots-clés dans ces deux langues.

Les articles pourront être accompagnés de planches en noir et blanc.

Les comptes rendus compteront de 4500 à 6000 signes.

Site web avec Présentation, Sommaire de tous les Numéros et Bulletin d’Abonnement

http://plh.univ-tlse2.fr

Revues.org : http://anabases.revues.org

\section{Courrier}

Pour les articles :

Clément Bur (clement.bur@univ-jfc.fr)

Catherine VALENTI (catherine.valenti@univ-tlse2.fr)

Pour les comptes rendus :

NoémieVILlacÈQue (noemie.villaceque@univ-reims.fr)

Université Toulouse-Jean Jaurès (UT2J)

Équipe P.L.H. - E.R.A.S.M.E. (EA4601)

Maison de la recherche (MdR)

5, allées Antonio Machado

F-31058 Toulouse Cedex 9

Tél. : 0033/(0)5.61.50.25.56 et 57

Fax : 0033/(0)5.61.50.24.90 


\section{Historiographie et identités culturelles}

Carole QuATRELIVRe, Le sanctuaire gaulois de Gournay-sur-Aronde (Oise). Retour sur une découverte exceptionnelle des années 1970

\section{Traditions du patrimoine antique}

Christophe CorbIER, Le pindarisme et l'archéologie musicale : style, valeur et authenticité de la première Pythique à l'époque moderne

Arnaud AmiLien, Hélène en Égypte : Hérodote en dialogue avec l'épopée

\section{Archéologie des savoirs}

Sébastien CAzalas, Au jardin des exempla. Rhétorique et stratégie de l'exemplum antique dans l'œuvre politique de Jean Juvénal des Ursins (1388-1473)

Dossier - Perpétuer Ovide : aspects moraux, éditoriaux, linguistiques et culturels $\left(\mathrm{xIV}^{\mathrm{e}}-\mathrm{XvIII}{ }^{\mathrm{e}} \mathrm{s}\right.$.)

Francesca DelL'Oro, Introduction

Hélène Casanova-Robin, L'audace châtiée : Phaéton, Actéon et Icare dans la tradition latine jusqu'à la Renaissance, tours et détours d'un symbolisme

Dylan Bovet, Le commentaire latin des Métamorphoses d'Ovide : pratiques humanistes et évolutions de Regius-Micyllus (1543) à Burmann-Heinsius (I727)

Martine Furno, Ovide en classe, ou un auteur en éclats

Basil Neurs, D'un Ovide chrétien à un Ovide burlesque, du Moyen Âge au Grand Siècle : continuités et changements dans la traduction et dans l'illustration des Métamorphoses perçus à travers deux éditions du xvir siècle

Olivier ThÉvenaz, Épilogue

\section{Actualités et débats}

Tiphaine-Annabelle BESNARD, 2019 : l'année pop des musées d'archéologie. Retour sur l'exposition romaine Il classico si fa pop. Di scavi, copie e altri pasticci

\section{Relire les classiques des sciences de l'Antiquité}

Jean-Pierre AıBERT, Le premier Detienne : une relecture de « La notion mythique d'A $\lambda \hat{\eta} \theta \varepsilon\llcorner\alpha$ » (REG, 1960, p. 27-35)

Marcel DetIENNE, La notion mythique d'A $\lambda \hat{\eta} \theta \varepsilon \varepsilon \alpha$

\section{L'atelier de l'histoire : chantiers historiographiques}

Antiquités numériques (coordonné par Élodie Guillon) (1)

Élodie GuILLON, Introduction

Jaime ALvar, Le projet EPIDI : Epítetos divinos. Experiencia religiosay relaciones de poder en Hispania

Les mots de l'Antiquité (coordonné par Magali Soulatges) (10)

Jack Tномаs, L’Antiquité dans les toponymes de l’État de New York

Actualité du théâtre (coordonné par Malika Bastin-Hammou) (4)

Mathieu Ferrand, “Avons-nous perdu le Soleil ? / Ou l'avons-nous chassé ? ”

Thyeste de Sénèque, traduit par Florence Dupont. Mise en scène de

Thomas Jolly (Avignon, 2018).

Voyages et Voyageurs (coordonné parVéronique Krings) (11)

Claude Azıza, Freud à Pompéi

\section{Comptes rendus de lecture}

